\title{
Review Article \\ Regulation of MicroRNAs by Natural Agents: New Strategies in Cancer Therapies
}

\author{
Neoh Hun Phuah ${ }^{1}$ and Noor Hasima Nagoor ${ }^{1,2}$ \\ ${ }^{1}$ Institute of Biological Science (Genetics and Molecular Biology), Faculty of Science, University of Malaya, \\ 50603 Kuala Lumpur, Malaysia \\ ${ }^{2}$ Centre for Research in Biotechnology for Agriculture (CEBAR), University of Malaya, 50603 Kuala Lumpur, Malaysia \\ Correspondence should be addressed to Noor Hasima Nagoor; hasima@um.edu.my
}

Received 4 July 2014; Accepted 14 August 2014; Published 1 September 2014

Academic Editor: Ajay Singh

Copyright (C) 2014 N. H. Phuah and N. H. Nagoor. This is an open access article distributed under the Creative Commons Attribution License, which permits unrestricted use, distribution, and reproduction in any medium, provided the original work is properly cited.

\begin{abstract}
MicroRNAs (miRNAs) are short noncoding RNA which regulate gene expression by messenger RNA (mRNA) degradation or translation repression. The plethora of published reports in recent years demonstrated that they play fundamental roles in many biological processes, such as carcinogenesis, angiogenesis, programmed cell death, cell proliferation, invasion, migration, and differentiation by acting as tumour suppressor or oncogene, and aberrations in their expressions have been linked to onset and progression of various cancers. Furthermore, each miRNA is capable of regulating the expression of many genes, allowing them to simultaneously regulate multiple cellular signalling pathways. Hence, miRNAs have the potential to be used as biomarkers for cancer diagnosis and prognosis as well as therapeutic targets. Recent studies have shown that natural agents such as curcumin, resveratrol, genistein, epigallocatechin-3-gallate, indole-3-carbinol, and 3,3' -diindolylmethane exert their antiproliferative and/or proapoptotic effects through the regulation of one or more miRNAs. Therefore, this review will look at the regulation of miRNAs by natural agents as a means to potentially enhance the efficacy of conventional chemotherapy through combinatorial therapies. It is hoped that this would provide new strategies in cancer therapies to improve overall response and survival outcome in cancer patients.
\end{abstract}

\section{Introduction}

According to a report by GLOBOCAN, an estimated 14.1 million new cancer cases and 8.2 million cancer deaths were reported, while 32.6 million people are found to be living with cancer (diagnosed in the past five years) in 2012 worldwide. The same report also projected that the number of new cases would increase to 19.3 million by 2025 due to global population aging. In 2012, the cancers of the lung (1.8 million, $13.0 \%$ of the total), breast (1.7 million, $11.9 \%$ ), and colorectum (1.4 million, 9.7\%) were the most commonly diagnosed cancers worldwide, while the most common causes of cancer death were cancers of the lung (1.6 million, $19.4 \%$ of the total), liver (0.8 million, 9.1\%), and stomach (0.7 million, $8.8 \%$ ) [1].

Cancer is a group of diseases characterized by the uncontrollable growth and spread of abnormal cells which can lead to death without timely intervention. Surgery, radiation, and chemotherapy are among the modalities used in cancer treatment, whose goal is to either cure the disease or prolong and improve the patient's quality of life. Although chemotherapy has led to improvement in this manner, drug resistance and toxicities remain major obstacles to improving the overall response and survival of cancer patients [2]. Drug resistance can be divided into two categories: intrinsic (also known as de novo) or acquired resistance [3]. Intrinsic resistance results in ineffective therapy from the start due to presence of resistant phenotype in the tumour cells. On the other hand, acquired resistance develops during treatment whereby tumour cells showed initial responsiveness towards anticancer drugs but attained resistant phenotype during the treatment course. This renders subsequent therapy ineffective leading to tumour recurrence and progression [3]. Hence, 
there is an urgent need to identify safer but equally effective agents to be used in cancer treatments, which can be found in natural agents.

The use of natural agents is promising because not only do they have minimal toxicity to humans compared to conventional chemotherapies, but also they could target numerous signalling pathways. This is beneficial as malignant transformation and progression are multistage processes caused by gene alterations in more than one signalling pathway. This is one of the most plausible explanations why monomodal therapy typically fails in cancer treatments as the specific inhibitors often target only a single gene in a signalling pathway [4]. Therefore, the impact of natural agents on cancer treatment could be more efficacious, as they can be used alone or as adjuvant in combination chemotherapy to improve therapeutic efficacy by overcoming drug resistance and/or reducing drug-induced toxicities. Hence, many of the anticancer agents currently used in cancer therapies have been developed from natural products such as plants (vincristine, vinblastine, etoposide, paclitaxel, camptothecin, topotecan, and irinotecan), marine organisms (cytarabine), and microorganisms (dactinomycin, bleomycin, and doxorubicin) [5]. Besides these, there are also plant-derived dietary polyphenols such as curcumin [6], resveratrol $[7,8]$, genistein [9], epigallocatechin-3-gallate [10], indole-3-carbinol, and its derivative $3,3^{\prime}$-diindolylmethane $[11,12]$ (see Figure 1). A number of studies involving cultured cancer cells and animal models have illustrated the protective role of these dietary polyphenols, and mechanistic studies have demonstrated that they exert their antiproliferative and/or proapoptotic effects to prevent the occurrence and/or spread of various cancers by targeting numerous key elements in intracellular signalling network involved in carcinogenesis $[13,14]$. Because of the promising results from these in vitro and in vivo studies, the efficacies of these natural agents in cancer therapies are being investigated in clinical trials (http://www.clinicaltrials.gov/) (see Table 1).

MicroRNAs (miRNAs) are highly conserved, small ( 22 nucleotides long) noncoding RNA molecules that regulate genes posttranscriptionally [15]. They are predicted to regulate the expression of around $60 \%$ of mammalian genes [16] and are found in abundance in many human cell types [17], making them one of the largest class of gene regulators. Although the miRNA genes are mostly found in the intergenic regions, they can also be present in the exonic and intronic regions, in all human chromosomes except for Y chromosome [18]. They are first transcribed by RNA polymerase II as long primary miRNA molecules (primiRNAs) before being processed into short hairpin RNAs of $\sim 70$ nucleotides known as pre-miRNA by Drosha (RNase III enzyme) and DGCR8 (DiGeorge syndrome critical region 8) [19]. It is then transported into the cytoplasm in a RanGTPdependent manner by Exportin- 5 to be cleaved by another RNase III enzyme, Dicer, to release a $\sim 22$ nucleotides long miRNA duplex $[20,21]$. One of the strands is incorporated into RNA-induced silencing complex (RISC) which directs miRNA binding to the $3^{\prime}$-untranslated regions ( $3^{\prime}$ UTR) of target mRNA resulting in mRNA silencing through target cleavage, mRNA degradation, and translation inhibition, while the complementary miRNA strand is usually rapidly degraded [21, 22] (see Figure 2). However, recent studies showed that they can also bind to other regions such as $5^{\prime}$ UTR or coding sequences $[23,24]$. Furthermore, they can also upregulate translation of target mRNAs by recruiting proteins complexes to the adenylate-uridylate- (AU-) rich elements of mRNA [25] or interfering with proteins that block the translation of target gene [26]. More interestingly, not only can a single gene be targeted by multiple miRNAs, a single miRNA can also target many genes [27]. miRNAs have been found to be dysregulated in nearly every types of human cancer [28] and various studies have implicated their involvement in a plethora of biological processes, such as tumorigenesis, cell differentiation, proliferation, death, autophagy, metastasis, and drug resistance [29-34]. Hence, identification of these oncogenic or tumour suppressive miRNAs allows for their use as potential targets in cancer therapies $[35,36]$.

Since natural agents exert their anticancer effects by targeting multiple signalling pathways, and miRNAs regulate diverse biological processes including cell proliferation and programmed cell death, it is thought that miRNAs could play a role in regulating response towards natural agents. Hence, miRNA regulation by natural agents in cancer therapy has been gaining greater attention in recent years. Various studies have reported the dysregulation in the miRNA expression profiles following treatment with natural agents, either as stand-alone or in combination with FDA-approved chemotherapeutic drugs. In one such study, we have previously reported that miRNAs are differentially expressed in response to different treatments, and bioinformatic analysis found their gene targets to be involved in regulating various signalling pathways including apoptosis and cell proliferation [37]. In this review, it was found that most of these dysregulated miRNAs target oncogenes, tumour suppressor genes, and transcription factors (see Tables 2, 3, and 4), and inhibition and/or overexpression of these miRNAs affect cell migration, invasion, proliferation, and apoptosis (see Figure 3). Beside these, there are also studies which found miRNAs to be dysregulated in response to these natural agents, although their targets were not confirmed (these miRNAs are subsequently discussed under "Other miRNAs" section). Therefore, insights from these studies could provide us with a better understanding in the interactions between miRNAs with their specific gene targets and, consequently, help us to delineate the molecular mechanism underlying anticancer drug response.

\section{Curcumin}

Curcumin (diferuloylmethane) is a natural compound derived from the rhizomes of turmeric (Curcuma longa) that inhibits cell proliferation, invasion, migration, angiogenesis, and inflammation and induces cell cycle arrest and apoptosis on various cancers, such as breast, cervical, oral, gastric, melanoma, pancreatic, colon, and prostrate [14, 38, 39]. It exhibits its anticancer effects by regulating genes involved in cellular signalling pathways, including nuclear factor-kappa 
<smiles>COc1cc(/C=C/C(=O)CC(=O)/C=C/c2ccc(O)c(OC)c2)ccc1O</smiles><smiles>Oc1ccc(CCc2cc(O)cc(O)c2)cc1</smiles><smiles>O=C1c2c(O)cc(O)cc2OCC1c1ccc(O)cc1</smiles><smiles>O=C(O[C@H]1CC2C(O)CC(O)=CC2OC1[C@H]1C=C(O)C(O)=C(O)C1)C1C=C(O)C(O)C(O)C1</smiles>

Resveratrol<smiles>C=CC(OC(C)=O)c1ccc(OC(C)=O)cc1</smiles>

$1^{\prime} S-1$-acetoxychavicol acetate<smiles>OCc1c[nH]c2ccccc12</smiles>

Indole-3-carbinol

Epigallocatechin-3-gallate<smiles>c1ccc2c(Cc3c[nH]c4ccccc34)c[nH]c2c1</smiles>

3, $3^{\prime}$-diindolylmethane<smiles>O=c1c(O)c(-c2ccc(O)c(O)c2)oc2cc(O)cc(O)c12</smiles><smiles>O=C(OCC(O)COC(=O)c1cc(O)c(O)c(O)c1)c1cc(O)c(O)c(O)c1</smiles>

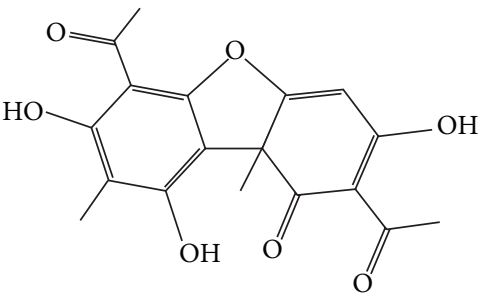

Ursolic acid Ellagitannin

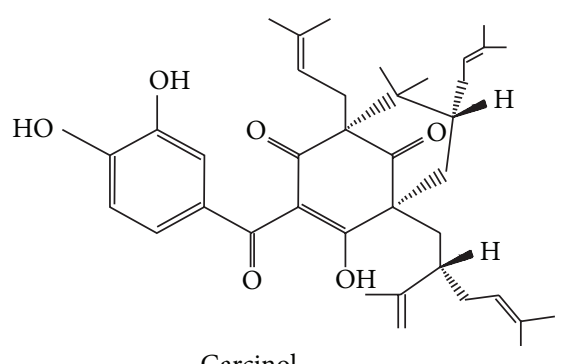

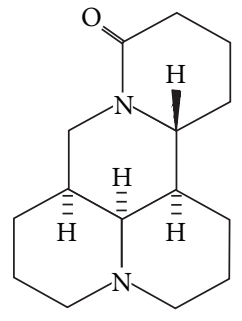

Matrine

FIGURE 1: Molecular structures of natural agents regulating miRNAs. 


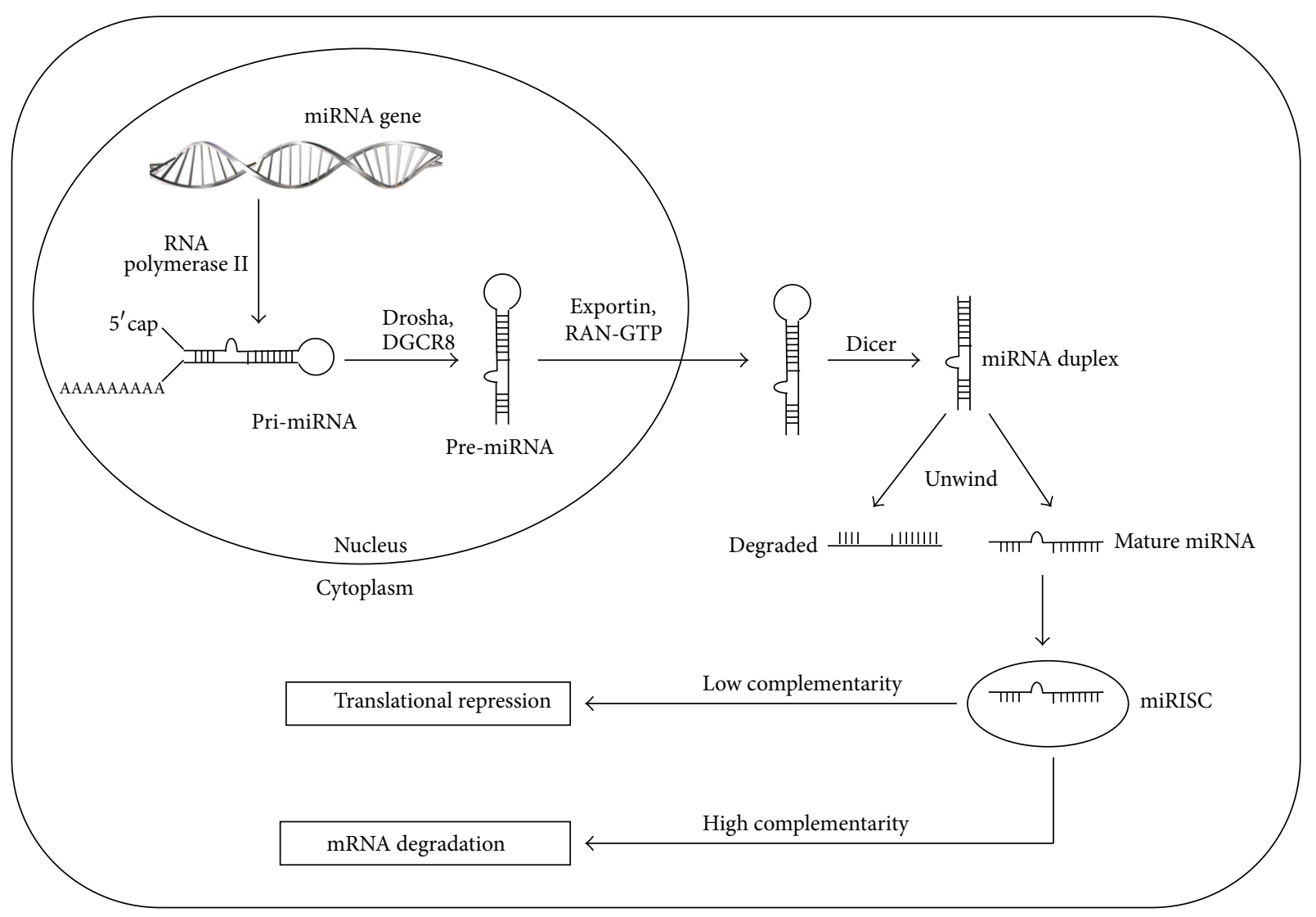

Figure 2: Biogenesis of miRNAs.

$\mathrm{B}(\mathrm{NF}-\kappa \mathrm{B})$, protein kinase $\mathrm{B}(\mathrm{Akt})$, mitogen-activated protein kinase (MAPK), p53, and other pathways [40].

2.1. miRNAs Targeting Oncogenes. Curcumin inhibited proliferation and induced apoptosis through upregulation of miR-181b in MDA-MB-231 breast cancer cells. This miRNA inhibited the expression of matrix metalloproteinases (MMP) by binding to metastases related-cytokines, such as chemokine (C-X-C motif) ligands 1 and 2 (CXCL1 and CXCL2), leading to reduced invasion in both in vitro and in vivo models. More importantly, it was shown that curcumin upregulated miR-181b and downregulated CXCL1 in tumour cells isolated from primary breast cancers, verifying the clinical significance of their results [41]. Yang et al. reported that curcumin induced apoptosis in MCF7 breast adenocarcinoma cells through downregulation of B-cell lymphoma 2 (Bcl-2) expression, a key antiapoptotic protein, as well as upregulation of miR-15a and miR-16. Inhibition of these miRNAs restored the expression of Bcl2 partially and induced cell proliferation [42]. Another study also reported the upregulation of these miRNAs upon treatment in K-562 and HL-60 leukemic cells, and inhibition of these miRNAs partly reversed the downregulation of Wilm's tumour 1 (WT1) induced by curcumin to promote cell growth [43]. A study in 2011 by Saini et al. revealed that curcumin induced hypomethylation of the tumour suppressive miR-203 promoter to increase its expression. This led to downregulation of its two targets, protein kinase B $\beta$ (Akt2) and $v$-Src avian sarcoma viral oncogene homolog (Src), culminating in increased apoptosis as well as decreased proliferation, migration, and invasion in T24 bladder cancer cells [44]. A total of $21 \mathrm{miRNAs}$ were found to be dysregulated (5 upregulated and 16 downregulated) in Y26 retinoblastoma cells treated with curcumin. Among the upregulated miRNAs is miR-22, and its overexpression inhibited cell proliferation and migration. The erythoblastic leukemia viral oncogene homolog 3 (Erbb3) was confirmed as its target in the same study [45].

2.2. miRNAs Targeting Tumour Suppressor Genes. Besides that, curcumin suppressed proliferation and induced apoptosis in A549 lung adenocarcinoma cells through downregulation of miR-186*, suggesting its potential role as an oncogenic miRNA. Interestingly, caspase-10 was identified as a direct target of this miRNA [46]. The same group demonstrated similar effects of miR-186* in A549/DDP multidrugresistant human lung adenocarcinoma cells [47]. In RKO and HCT116 colon cancer cells, the expression of miR-21 which correlated with the inhibition of activator protein-1 (AP-1) binding to its promoter was reduced following treatment with curcumin. Consequently, cell proliferation, tumour growth, invasion, and in vivo metastasis were suppressed, while the expression of the tumour suppressor programmed cell death protein 4 (PDCD4), a target of miR-21, was 

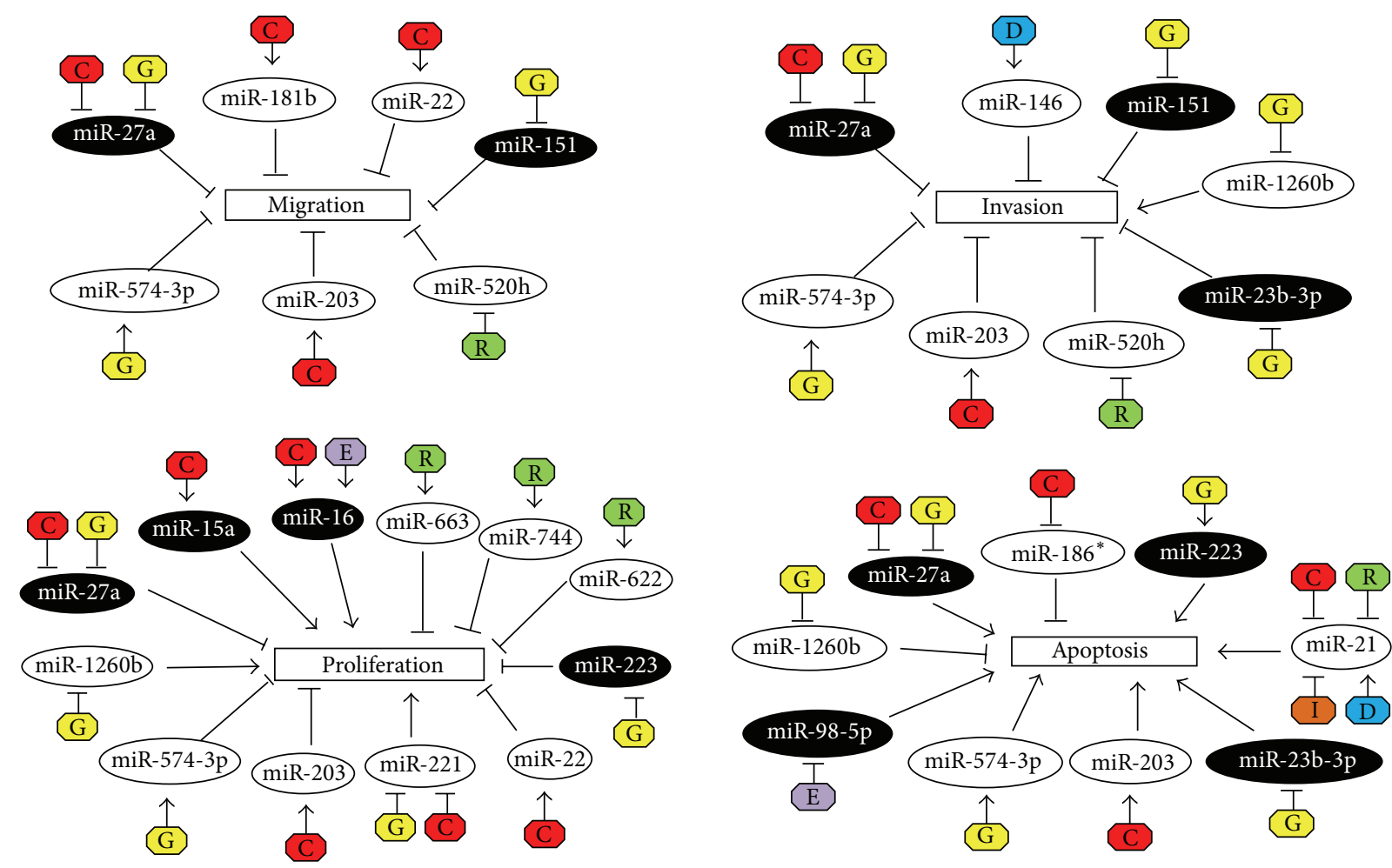

(C) Curcumin

R Resveratrol

G Genistein

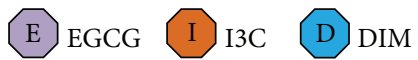

FIGURE 3: Regulation of miRNAs by natural agents and effects of miRNA inhibition (black ellipse) or overexpression (white ellipse) on cell migration, invasion, proliferation, and apoptosis. Inhibitory relationships are denoted as flat arrow heads, whereas positive interactions are denoted as open arrow heads.

upregulated [48]. In another study, curcumin induced cell cycle arrest and apoptosis through downregulation of Notch1 specific miR-21 and miR-34a, and upregulation of tumour suppressor let-7a, in TE-7 human esophageal cancer cells [49]. Meanwhile, Liang et al. revealed that curcumin induced apoptosis in HepG2 and HepJ5 hepatocellular carcinoma cells by downregulating Bcl-2 level and upregulating Bcl-2associated death promoter (BAD) level. Their data indicated that overexpression of miR-200a and miR-200b resulted in resistance towards curcumin through reduced apoptotic effect. A decrease in the level of proapoptotic $\mathrm{BAD}$ and $\mathrm{Bcl}-2$ associated X protein (BAX) was found in miR-200a- and miR200b-over-expressed cells, while an increase in Bcl-2 level was only observed in miR-200b, with no changes in miR200a-over-expressed cells. Taken together, these data suggest that overexpression of these miRNAs conferred resistance towards curcumin through regulation of the Bcl-2 family [50].

2.3. miRNAs Targeting Transcription Factors. Curcumin was found to upregulate 11 and downregulate 18 miRNAs in BxPC-3 human pancreatic adenocarcinoma cells. Of these, the most prominent upregulated miRNA is miR-22 while the most downregulated miRNA is miR-199*. Importantly, miR-22 upregulation decreased the expression of specificity protein 1 (SP1) and estrogen receptor 1 (ESR1) and vice versa, suggesting that they are targets of miR-22 [78]. The significant relationship between ESR1 gene amplification, which affects the cellular responsiveness to estrogen and antiestrogen, and breast cancer has been reported previously $[84,85]$. On the other hand, SP1 proteins play a role in the growth and metastases in various tumour types by regulating cell cycle gene expression and vascular endothelial growth factor receptor [86]. Besides that, curcumin inhibited the growth of RKO and SW480 colon cancer cells through induction of reactive oxygen species (ROS) and repression of specificity proteins (Sp) transcription factors through downregulation of miR27a, miR-20a, and miR-17-5p. These miRNAs regulate $\mathrm{Sp}$ repressors, zinc finger, and BTB domain-containing proteins 4 and 10 (ZBTB4 and ZBTB10) [79]. This has important implications as Sp proteins are transcription factors that regulate genes involved in cell death and angiogenesis and are often overexpressed in tumours $[87,88]$.

\section{Resveratrol}

Resveratrol (3,4',5-trihydroxystilbene) is a natural phytoalexin present in several plants, such as grapes, berries, plums, and peanuts. The anticancer effects are mediated 
TABLE 1: Clinical trials involving selected natural agents.

\begin{tabular}{|c|c|c|c|c|}
\hline Natural agent & Trial identifier & Phase & Cancer type & Status \\
\hline \multirow{20}{*}{ Curcumin } & NCT01042938 & 2 & Breast & Completed \\
\hline & NCT00094445 & 2 & Pancreatic & Completed \\
\hline & NCT00192842 & 2 & Pancreatic & Completed \\
\hline & NCT01333917 & 1 & Colorectal & Completed \\
\hline & NCT00027495 & 1 & Colorectal & Completed \\
\hline & NCT01035580 & 1 & Uterine cervical & Completed \\
\hline & NCT00113841 & n.a & Multiple myeloma & Completed \\
\hline & NCT01975363 & n.a & Breast & Active \\
\hline & NCT01859858 & 1 & Colorectal & Active \\
\hline & NCT00745134 & 2 & Rectal & Active \\
\hline & NCT01294072 & 1 & Colon & Active \\
\hline & NCT01917890 & n.a & Prostate & Active \\
\hline & NCT01160302 & 0 & Head and neck & Active \\
\hline & NCT01490996 & $1 / 2$ & Colon & Active \\
\hline & NCT02095717 & 2 & Prostate & Active \\
\hline & NCT02017353 & 2 & Endometrial & Active \\
\hline & NCT02064673 & 2 & Prostate & Active \\
\hline & NCT00641147 & n.a & Familial adenomatous Polyposis & Active \\
\hline & NCT00927485 & n.a & Familial adenomatous Polyposis & Active \\
\hline & NCT01948661 & 2 & Colorectal & Active \\
\hline \multirow{4}{*}{ Resveratrol } & NCT00256334 & 1 & Colon & Completed \\
\hline & NCT00433576 & 1 & Colorectal & Completed \\
\hline & NCT00098969 & 1 & Solid tumours & Completed \\
\hline & NCT01476592 & n.a & Neuroendocrine & Active \\
\hline \multirow{14}{*}{ Genistein } & NCT00244933 & 2 & Breast & Completed \\
\hline & NCT00118040 & 2 & Bladder & Completed \\
\hline & NCT00099008 & 1 & Breast & Completed \\
\hline & NCT00584532 & $2 / 3$ & Prostate & Completed \\
\hline & NCT00376948 & 2 & Pancreatic & Completed \\
\hline & NCT00269555 & n.a & Prostate & Completed \\
\hline & NCT00499408 & 2 & Prostate & Completed \\
\hline & NCT00078923 & 2 & Prostate & Completed \\
\hline & NCT01985763 & $1 / 2$ & Colorectal & Active \\
\hline & NCT01325311 & 2 & Prostate & Active \\
\hline & NCT01126879 & 2 & Prostate & Active \\
\hline & NCT01628471 & $1 / 2$ & Lung & Active \\
\hline & NCT00276835 & 0 & Kidney; melanoma & Active \\
\hline & NCT01182246 & $1 / 2$ & Pancreatic & Active \\
\hline \multirow{13}{*}{ EGCG } & NCT00459407 & 1 & Prostate & Completed \\
\hline & NCT00233935 & 1 & Esophageal & Completed \\
\hline & NCT00573885 & 2 & Lung & Completed \\
\hline & NCT00303823 & 2 & Cervical & Completed \\
\hline & NCT01105338 & $2 / 3$ & Prostate & Completed \\
\hline & NCT00516243 & 1 & Breast & Active \\
\hline & NCT00942422 & 2 & Multiple myeloma & Active \\
\hline & NCT00596011 & 2 & Prostate & Active \\
\hline & NCT01606124 & 2 & Colorectal & Active \\
\hline & NCT00253643 & n.a & Prostate & Active \\
\hline & NCT00917735 & 2 & Breast & Active \\
\hline & NCT01360320 & 2 & Colorectal & Active \\
\hline & NCT00949923 & 1 & Breast & Active \\
\hline
\end{tabular}


TABle 1: Continued.

\begin{tabular}{lcccc}
\hline Natural agent & Trial identifier & Phase & Cancer type & Status \\
\hline \multirow{2}{*}{ I3C } & NCT00607932 & n.a & Prostate & Completed \\
& NCT00033345 & 1 & Breast & Completed \\
& NCT00100958 & 1 & Solid tumours & Completed \\
\hline \multirow{3}{*}{ DIM } & NCT00450229 & 1 & Prostate & Completed \\
& NCT00305747 & 1 & Prostate & Completed \\
& NCT00462813 & 3 & Cervical & Active \\
& NCT00888654 & 2 & Prostate & Active \\
\hline
\end{tabular}

TABLE 2: Selected miRNAs targeting oncogenes.

\begin{tabular}{|c|c|c|c|c|c|}
\hline Natural agent & miRNA & Regulation & Target(s) and function(s) & Cancer type & Reference \\
\hline \multirow{4}{*}{ Curcumin } & miR-181b & Up & $\begin{array}{l}\text { Targets CXCL1 and CXCL2; inhibited migration through } \\
\text { MMP }\end{array}$ & Breast & [41] \\
\hline & miR-15a, miR-16 & Up & $\begin{array}{l}\text { miRNA inhibition upregulates Bcl-2 and WT1 and induces } \\
\text { cell growth }\end{array}$ & Breast; leukemia & {$[42,43]$} \\
\hline & miR-203 & Up & $\begin{array}{l}\text { Targets Akt2 and Src; inhibits cell proliferation, invasion, } \\
\text { and migration; and induces cell cycle arrest and apoptosis }\end{array}$ & Bladder & {$[44]$} \\
\hline & miR-22 & Up & Targets Erbb3; inhibits cell proliferation and migration & Pancreatic & {$[45]$} \\
\hline \multirow{3}{*}{ Resveratrol } & miR-663, miR-744 & Up & Targets eEF1A; inhibits cell proliferation & Breast & {$[51]$} \\
\hline & $\operatorname{miR}-21$ & Down & Upregulates Bcl-2; increases apoptosis & Pancreatic & {$[52]$} \\
\hline & $\operatorname{miR}-622$ & Up & $\begin{array}{l}\text { Targets K-Ras; inhibits proliferation and colony formation } \\
\text { in vitro and tumorigenicity in vivo }\end{array}$ & Lung & [53] \\
\hline \multirow{3}{*}{ Genistein } & miR-34a & Up & Targets HOTAIR & Prostate & {$[54]$} \\
\hline & miR-574-3p & Up & $\begin{array}{l}\text { Targets RACl, EGFR, and EP300; inhibits cell } \\
\text { proliferation, migration, and invasion; and induces } \\
\text { apoptosis }\end{array}$ & Prostate & {$[55]$} \\
\hline & miR-1296 & Up & miRNA inhibition upregulates MCM2 and vice versa & Prostate & {$[56]$} \\
\hline EGCG & miR-16 & Up & Targets Bcl-2 & Hepatocellular & {$[57]$} \\
\hline \multirow{3}{*}{ DIM } & miR-21 & $\mathrm{Up}$ & Targets Cdc25A & Pancreatic & {$[58]$} \\
\hline & let-7 family & Up & Downregulates EZH2 & Prostate & [59] \\
\hline & miR-146 & Up & $\begin{array}{l}\text { Downregulates EGFR, IRAK-1, NF-kB, and MTA2; } \\
\text { inhibits cell invasion }\end{array}$ & Pancreatic & {$[60]$} \\
\hline
\end{tabular}

through three main mechanisms: inhibition of carcinogenic activation and induction of carcinogen detoxification, induction of growth arrest and apoptosis, and suppression of proinflammatory signalling pathways related to cancer progression [89].

3.1. miRNAs Targeting Oncogenes. Treatment with resveratrol in MCF-7 breast adenocarcinoma cells upregulated miR-663 and miR-774, which were able to retard cell proliferation by inhibiting eukaryotic translation elongation factor 1A2 (eEF1A2) at mRNA and protein levels [51]. Liu et al. also reported downregulation of miR-21 by resveratrol in PANC1, CFPAC-1, and MIA Paca-2 pancreatic cancer cells, leading to inhibition of Bcl-2 expression. Overexpression of miR-21 was found to reverse downregulation of Bcl-2 and resveratrolinduced apoptosis [52]. In anti-benzo[a]pyrene-7,8-diol-9,10epoxide-transformed human bronchial epithelial cell line (16HBE-T), resveratrol upregulated miR-622, which targets Kirsten rat sarcoma viral oncogene homolog (K-Ras), to inhibit cell proliferation, induce cell cycle arrest at $G_{0}$ phase, and suppress colonies formation in vitro and tumorigenicity in nude mice, while its downregulation impaired growth inhibition. Moreover, it was shown that the binding of miR622 to K-Ras $3^{\prime}$ UTR was affected by resveratrol [53].

3.2. miRNAs Targeting Tumour Suppressor Genes. Resveratrol upregulated miR-663 in SW480 human colon cancer cells, besides downregulating various other miRNAs usually found to be overexpressed in this cancer, such as miR-17, miR-21, miR-25, miR-26a, miR-92a-2, miR-103-1 and -1032 , and miR-181a2. The transforming growth factor beta 1 (TGF $\beta 1$ ) transcript was identified as a target of miR-663 [61]. On the other hand, prostate cancer cells treated with resveratrol displayed downregulation of several miRNAs, including the oncogenic miR-17-92 and miR-106ab clusters. These miRNAs target phosphatase and tensin homologue deleted on chromosome 10 (PTEN), a tumour suppressor protein that is downregulated in nearly all cancers [62]. 
TABLE 3: Selected miRNAs targeting tumour suppressor genes.

\begin{tabular}{|c|c|c|c|c|c|}
\hline Natural agent & miRNA & Regulation & Target(s) and function(s) & Cancer type & Reference \\
\hline \multirow{2}{*}{ Curcumin } & miR-186* & Down & Targets caspase-10; inhibits apoptosis & Lung & {$[46,47]$} \\
\hline & miR-21 & Down & Targets PDCD4 & Colon & {$[48]$} \\
\hline \multirow{3}{*}{ Resveratrol } & miR-663 & Up & Targets TGF $\beta 1$ & Colon & [61] \\
\hline & miR-17-92, miR-10ab & Down & Targets PTEN & Prostate & {$[62]$} \\
\hline & miR-21 & Down & Targets PDCD4 and maspin & Prostate & {$[63,64]$} \\
\hline \multirow{6}{*}{ Genistein } & miR-221, miR-222 & Down & Targets ARH1 & Prostate & {$[65]$} \\
\hline & miR-151 & Down & $\begin{array}{l}\text { miRNA inhibition suppresses cell migration and } \\
\text { invasion; targets N4BP1, CASZ1, IL1RAPL1, SOX17, } \\
\text { and ARHGDIA }\end{array}$ & Prostate & {$[66]$} \\
\hline & miR-23b-3p & Down & $\begin{array}{l}\text { Targets PTEN; miRNA inhibition induces apoptosis } \\
\text { and inhibits invasion }\end{array}$ & Renal & {$[67]$} \\
\hline & miR-1260b & Down & $\begin{array}{l}\text { Targets sFRP1, Dkk2 and, Smad4; induces cell } \\
\text { proliferation and invasion; inhibits apoptosis }\end{array}$ & Renal; Prostate & {$[68,69]$} \\
\hline & miR-223 & Down & $\begin{array}{l}\text { Upregulates Fbw7; miRNA inhibition suppresses cell } \\
\text { growth and induces apoptosis }\end{array}$ & Pancreatic & {$[70]$} \\
\hline & miR-27a & Down & $\begin{array}{l}\text { Upregulates ZBTB10 and Sprouty2; miRNA } \\
\text { inhibition suppresses cell growth, migration, and } \\
\text { invasion and induces apoptosis }\end{array}$ & $\begin{array}{l}\text { Melanoma; } \\
\text { Ovarian; } \\
\text { Pancreatic }\end{array}$ & {$[71-73]$} \\
\hline EGCG & miR-98-5p & Down & $\begin{array}{l}\text { miRNA inhibition enhances cisplatin-induced } \\
\text { apoptosis and increases p53 expression }\end{array}$ & Lung & {$[74]$} \\
\hline \multirow{2}{*}{$\mathrm{I} 3 \mathrm{C}$} & miR-21 & Down & Downregulates PTEN, PDCD4, and RECK & Lung; Pancreatic & {$[75,76]$} \\
\hline & miR-221 & Down & $\begin{array}{l}\text { Upregulates PTEN, p27kip1, p57kip2, and PUMA; } \\
\text { increases cell proliferation }\end{array}$ & Pancreatic & [77] \\
\hline
\end{tabular}

TABLE 4: Selected miRNAs targeting transcription factors.

\begin{tabular}{|c|c|c|c|c|c|}
\hline Natural agent & miRNA & Regulation & Target(s) and function(s) & Cancer type & Reference \\
\hline \multirow{2}{*}{ Curcumin } & $\operatorname{miR}-22$ & Up & $\begin{array}{l}\text { miRNA inhibition upregulates SP1 and ESR1 expression } \\
\text { and vice versa }\end{array}$ & Pancreatic & {$[78]$} \\
\hline & $\begin{array}{l}\text { miR-27a, miR-20a, } \\
\text { miR-17-5p }\end{array}$ & Down & Targets ZBTB4 and ZBTB10 & Colon & [79] \\
\hline \multirow{3}{*}{ Resveratrol } & miR-34a & Up & Targets E2F3 & Colon & {$[80]$} \\
\hline & miR-520h & Down & $\begin{array}{l}\text { Inhibits cell migration and invasion, decreases levels of } \\
\text { FOXC2 }\end{array}$ & Lung & {$[81]$} \\
\hline & miR-663 & Up & Targets JunB and JunD; decreases miR-155 & Leukemia & {$[82]$} \\
\hline DIM & miR-200 & Down & $\begin{array}{l}\text { Targets ZEB1; downregulates ZEB1, slug, and vimentin; } \\
\text { upregulates E-cadherin }\end{array}$ & Pancreatic & {$[83]$} \\
\hline
\end{tabular}

In another study, resveratrol inhibited cell viability and invasion in highly invasive, androgen independent PC-3 MMM2 human prostate carcinoma cells, through suppression of Akt. This resulted in the inhibition of miR-21 along with induction of programmed cell death protein 4 (PDCD4) and maspin, targets of miR-21. Similar effects were observed in two other human prostate cancer cells, LNCap and DU145. Additionally, the in vitro results were corroborated in severe combined immunodeficient (SCID) mouse xenograft model of prostate cancer, suggesting that resveratrol mediated its effects through inhibition of Akt/miR-21 signalling pathway [63]. Resveratrol also downregulated miR-21 and upregulated PDCD4 in AGS gastric cancer cells. A reduced expression of PDCD4 and overexpression of miR-21 were found in gastric cancer specimens. Interestingly, there was a significant inverse correlation between miR-21 and PDCD4 protein expression, but not between their mRNA expression, suggesting posttranslational modification [64].

3.3. miRNAs Targeting Transcription Factors. Besides that, it was found that resveratrol upregulated miR-34a in DLD1 human colon cancer cells. The E2F transcription factor 3 (E2F3), a target of miR-34a, and E2F3's downstream target sirtuin (silent mating type information regulation 2 homolog) 1 (Sirt1) were downregulated following treatment, suggesting that resveratrol exerted its anticancer activity 
through miR-34a/E2F3/Sirtl cascade [80]. In a drug combination study, resveratrol and quercetin induced apoptosis in HT-29 human colon cancer cells by increasing caspase3 and poly ADP ribose polymerase (PARP) cleavage. The Sp1, Sp3, and Sp4 specificity proteins, together with Spregulated antiapoptotic protein, survivin, were reduced at both mRNA and protein levels. Moreover, this combination treatment also decreased miR-27a and induced ZBTB10 [90]. In a study involving CLI-5 and A549 lung adenocarcinoma cells, resveratrol downregulated miR-520h and triggered miR-520h-mediated signal cascade, resulting in inhibition of forkhead box C2 (FOXC2) and subsequent suppression of tumour metastasis in both in vitro and in vivo models. The same study showed association between expression of FOXC2 with epithelial-mesenchymal transition (EMT), cell motility, metastasis, and poorer prognosis in lung cancer patients [81]. Resveratrol upregulated miR-663 in THP-1 human monocytic cells and human blood monocytes. MiR663 decreased the activity of AP-1 by targeting JunB and JunD transcripts, and its upregulation decreased the levels of miR-155, which has been linked to formation and development of tumours such as breast, gastric, and lung cancers $[82,91]$.

3.4. Other miRNAs. In A549 human lung adenocarcinoma cells, resveratrol altered miRNA expression profiles, with downregulated miR-92a- $2^{*}$ and upregulated miR-299-5p, miR-194* , miR-338-3p, miR-758, and miR-582-3p exhibiting greater than 20 -fold changes. Importantly, identification of their targets through bioinformatics analyses revealed their involvement in regulating apoptosis, cell cycle, cell proliferation, and cell differentiation [92]. In another study, a number of tumour suppressive miRNAs including miR-141 and $\mathrm{miR}-200 \mathrm{c}$ were upregulated by resveratrol, inhibiting the breast cancer stem-like cell characteristics in MDA-MB-231luc-D3H2LN cells (a luciferase expressing cell line that was derived from MDA-MB-231 human breast adenocarcinoma cells). Repression of miR-141 resulted in increased cell invasion [93]. In p53 wild-type (MCF-7) and p53 mutant-type (MDA-MB-231 and BT-549) breast cancer cells, resveratrol suppressed pAkt and phosphorylation of CCAAT/enhancer binding protein beta $(\mathrm{C} / \mathrm{EBP}-\beta)$, which has been identified as a negative regulator of miR-145, leading to upregulation in this miRNA [94]. More recently, it was reported that resveratrol downregulated the expression of DNA methyltransferase 3b (DNMT3b) and upregulated miR-21, miR-129, miR-204, and miR-489 in hormone sensitive mammary tumours, but vice versa in matched normal mammary tissue. An inverse association between DNMT3b and miR-129, miR-204, and miR-489 expression in normal and tumour tissue was also found [95].

\section{Genistein}

Genistein is a isoflavone naturally found in numerous plants, including fava beans, lupins, and soybeans [96]. Previous reports have shown that it induces cell cycle arrest and apoptosis and inhibits angiogenesis and metastasis in various cancers including breast, prostate, gastric, lung, pancreatic, melanoma, and renal cancer in both in vitro and in vivo models. Besides having antioxidant properties, it also inhibits NF$\kappa \mathrm{B}$ and Akt signalling pathways and antagonizes estrogenand androgen-mediated signalling pathways [97].

4.1. miRNAs Targeting Oncogenes. In PC-3 and DU145 prostate cancer cells, genistein upregulated miR-34a with HOX transcript antisense RNA (HOTAIR) confirmed as its target. Knockdown of this gene decreased cell proliferation, migration, and invasion, and induced apoptosis and cell cycle arrest [54]. Also in the same cells, genistein upregulated miR-574-3p and overexpression of this miRNA inhibited cell proliferation, migration, and invasion in vitro and in vivo, and apoptosis was induced through reduction of $\mathrm{B}$ cell lymphocyte $\mathrm{xL}(\mathrm{Bcl}-\mathrm{xL})$ and activation of caspase-3 and -9 . The Ras-related C3 botulinum toxin substrate 1 (RAC1), epidermal growth factor receptor (EGFR), and E1A binding protein p300 (EP300) were confirmed as targets of miR-574-3p, and inhibition in cell proliferation, migration, and invasion was observed when these three targets were knocked down. The expression of miR-574-3p was found to be significantly lower in PC-3 and DU145 and prostate tumour tissues compared with RWPE-1 normal prostate cells and adjacent normal tissues, respectively. The low expression level of miR-574-3p correlated with advanced tumour stage and higher Gleason score [55]. Also in PC-3 prostate cancer cells, genistein upregulated miR-1296 and suppressed the expression of minichromosome maintenance (MCM) gene family, which is essential for DNA replication and frequently found to be upregulated in various cancers. Inhibition of miR1296 resulted in upregulation of MCM2 mRNA and protein and vice versa, strongly suggesting MCM2 as its target. Furthermore, MCM2 expression correlated with prostate cancer progression, whereby reduced expression of miR-1296 was observed in prostate carcinoma compared to benign prostate hyperplasia [56].

4.2. miRNAs Targeting Tumour Suppressor Genes. Genistein also downregulated miR-221 and miR-222 in PC-3 prostate cancer cells, leading to upregulation of aplysia ras homolog I (ARH1), a target of these miRNAs. Overexpression of ARH1 led to inhibition of cell proliferation, colony formation, and invasion [65]. It was reported that miR-151 has higher expression in PC-3 and DU145 prostate cancer cells compared to RWPE-1, a nonmalignant epithelial prostate cell line. Genistein downregulated miR-151 and its suppression inhibited cell migration and invasion but not cell proliferation in the prostate cancer cells. Moreover, miR-151 was also shown to bind directly to the $3^{\prime}$ UTRs of NEDD4 binding protein 1 (N4BP1), castor zinc finger 1 (CASZ1), interleukin 1 receptor accessory protein-like 1 (IL1RAPL1), SRY (sex determining region Y)-box 17 (SOX17), and Rho GDP dissociation inhibitor (GDI) alpha (ARHGDIA). It was found that miR-151 expression is significantly higher in prostate cancer compared to the benign state, although a higher expression did not show significant correlation with lower survival rate [66]. Another miRNA whose expression 
is inhibited by genistein is miR-23b-3p, and its knockdown in A-498 and Caki-2 renal cancer cells resulted in significant apoptosis induction and reduction in invasive capabilities, but not cell cycle progression. Furthermore, miR-23b-3p was found to directly target PTEN and its inhibition induced PTEN expression with concomitant reduction in PI3-kinase, total Akt, and IL-32. The expression level of this miRNA was found to be inversely correlated with five-year survival rate in renal cancer patients, and lack of PTEN protein expression was observed in tissue samples with high miR23b-3p expression [67]. Also in renal cancer cells, genistein significantly decreased the expression of miR-1260b in 786$\mathrm{O}$ and A-498 cells and TCF reporter activity was found to be paralleled to its expression, indicative of its regulation of the $\beta$-catenin-dependent pathway. Furthermore, miR-1260b promoted cell proliferation and invasion while apoptosis was reduced in these cells. Tumour suppressors associated with Wnt-signalling such as secreted frizzled-related protein 1 (sFRP1), dickkopf 2 homolog (Dkk2), and mothers against decapentaplegic $4(\operatorname{Smad} 4)$ were confirmed as targets of miR-1260b, and their overexpression decreased cell proliferation and invasion along with increased apoptosis. More pertinently, miR-1260b has higher expression in renal cancer tissues compared to normal kidney tissues and its expression significantly correlates with shorter overall survival [68]. Similar results with miR-1260b were reported in PC-3 and DU-145 prostate cancer cells, suggesting the importance and potential therapeutic benefit of this miRNA in cancer treatment [69]. In a study by $\mathrm{Ma}$ et al., it was demonstrated that genistein downregulated miR-223 and upregulated its targets, F-box and WD-40 domain protein 7 (Fbw7). In addition, inhibition of miR-223 retarded cell growth and induced apoptosis in pancreatic cancer cells [70]. Genistein inhibited the expression of miR-27a in C918 uveal melanoma [71], SKOV3 ovarian cancer [72], and pancreatic cancer cells [73]. The expression of ZBTB10 and Sprouty2, targets of miR27a, was found to be upregulated following treatment, while inhibition of miR-27a suppressed cell growth, migration, and invasion and induced apoptosis in these cells [71-73]. In PC-3 prostate cancer cells, genistein in combination with 5-aza-20-deoxycytidine (5-aza) and trichostatin A (TSA) upregulated miR-145. Loss of miR-145 expression was frequently observed in prostate cancer cell lines and tissue samples compared to normal cells and matched adjacent normal tissues, respectively. This inactivation was seen as a result of DNA methylation in the miR-145 promoter region. Overexpression of miR-145 resulted in decreased cell viability, increased apoptosis, cell cycle arrest, and upregulation of proapoptotic tumour necrosis factor (ligand) superfamily, member 10 (TNFSF10) [98].

4.3. Other miRNAs. Various miRNAs were found to be dysregulated following treatment with genistein in prostate cancer cells: one upregulated (miR548b-3p) and four downregulated miRNAs (miR-15b, miR-125a, miR-125b, and miR$320)$ in PC-3 cells; five downregulated miRNAs (miR-155, miR-208b, miR-211, miR-376a, and miR-411) in DU-145 cells; one upregulated miRNA (miR-15a), and three downregulated
miRNAs (miR-494, miR-520g, and miR-542) in LNCap cells. These results showed that miRNAs are differentially expressed in different prostate cancer cells treated with genistein, although their roles were not investigated in the same study [99]. Genistein also inhibited miR-21 in A498 renal cancer cells and tumour xenografts, leading to cell cycle arrest, apoptosis induction, reduced invasion, and migration capabilities as well as increased expression of p21 and p38 MAPK but a reduction in cyclin E2. This study showed that patients with lower miR-21 expression have better five-year survival rate while increased expression correlates with an increased stage of renal cancer, providing clinical relevance in the role of miR-21 in renal cancer [100]. Additionally, genistein upregulated miR-34a in pancreatic cancer cells. Treatment with genistein and overexpression of miR-34a inhibited cell growth and induced apoptosis with concomitant downregulation of Notch-1 signalling pathway [101].

\section{Epigallocatechin-3-Gallate (EGCG)}

The epigallocatechin-3-gallate (EGCG) is the major polyphenol found in green tea (Camellia sinensis) with anticancer effects. Previous reports have shown that it is able to suppress proliferation, induce apoptosis, and inhibit invasion, angiogenesis, and metastasis in various cancer types in both in vitro and in vivo models by targeting multiple cellular signalling pathways $[102,103]$.

5.1. miRNAs Targeting Oncogenes. Treatment with EGCG in HepG2 hepatocellular carcinoma cells altered the expression of 61 miRNAs (13 upregulated and 48 downregulated) and among the upregulated miRNAs is miR-16. Its target, Bcl2, was also downregulated by EGCG. Suppression of miR-16 counteracted the effects of EGCG on apoptosis induction and Bcl-2 downregulation [57].

5.2. miRNAs Targeting Tumour Suppressor Genes. Besides that, it was also reported that EGCG enhanced the effects of cisplatin by downregulating miR-98-5p in A549 lung cancer cells. Inhibition of miR-98-5p enhanced cisplatin-induced cell death and increased expression of p53 [74].

5.3. Other miRNAs. In HepG 2 hepatocellular carcinoma cells, five miRNAs (miR-30b ${ }^{*}$, miR-453, miR-520-e, miR-629, and miR-608) were downregulated following treatment with EGCG. Bioinformatics analysis revealed gene targets of miR$30 \mathrm{~b}^{*}$ to be involved in regulating various pathways including inflammation, $\mathrm{NF}-\kappa \mathrm{B}$, peroxisome proliferator-activated receptor (PPAR) signalling, insulin signalling, glycolysis and gluconeogenesis, glycerolipid metabolism, mitochondria and oxidative phosphorylation, and glutathione metabolism [104]. EGCG upregulated miR-210, a key component of hypoxia-inducible factor $1 \alpha$ (HIF-1 $\alpha)$, through the hypoxiaresponse element found in the promoter region, in both H1299 and H460 non-small-cell lung cancer and CL13 mouse lung adenocarcinoma cell lines. Overexpression of miR-210 reduced cell proliferation rate and anchorage-independent 
growth [105]. In a study by Chakrabarti et al., it was reported that EGCG downregulated three oncogenic miRNAs (miR-92, miR-93, and miR-106b) and upregulated three tumour suppressive miRNAs (miR-7-1, miR-34a, andmiR99a), leading to induction of both intrinsic and extrinsic apoptotic pathways in SK-N-BE2 and IMR-32 malignant neuroblastoma cell lines. The alterations in expression of these miRNAs were found to be more significant when treated with EGCG in combination with $\mathrm{N}$-(4-hydroxyphenyl) retinamide (4-HPR), and overexpression of miR-93 and miR7-1, which exhibited the highest fold-change, decreased and increased efficacy towards EGCG, respectively [106]. The 4-HPR is a synthetic retinoid that has been reported by Reynolds et al., to induce differentiation of neuroblastoma cells and increase survival rates in neuroblastoma patients [107]. Overexpression of miR-93 and miR-7-1, which exhibited the highest fold-change, decreased and increased efficacy towards EGCG, respectively [107]. Similar results were reported on SH-SY5Y and SK-N-DZ malignant neuroblastoma cell lines when used as stand-alone agent [108]. Meanwhile, it was found that oncogenic miR-21 was downregulated while tumour suppressive miR-330 was upregulated in prostate cancer xenograft tissues of EGCG-treated mice [109].

\section{Indole-3-Carbinol (I3C) and 3,3' - Diindolylmethane (DIM)}

The indole-3-carbinol (I3C) is a naturally occurring glucosinolates found in the Brassica vegetables such as cabbage, broccoli, cauliflower, kale, radish, turnip, and brussels sprouts, while $3,3^{\prime}$-diindolylmethane (DIM) is a prominent product obtained when I3C undergoes condensation reactions in the stomach [110]. Both I3C and DIM have been reported to modulate many genes involved in regulating cell cycle, cell proliferation, signal transduction, apoptosis, and other cellular processes $[111,112]$.

6.1. miRNAs Targeting Oncogenes. Treatment with DIM upregulated mR-21 and downregulated its target, cell division cycle 25 homolog A (Cdc25A), leading to reduced cell proliferation in MCF-7 breast cancer cells. Consequently, repression of miR-21 elevated Cdc25A level, while treatment with DIM partially restored Cdc25A expression and enhanced cell proliferation [58]. It was also reported that DIM upregulated the expression of the let-7 family and reduced the expression of its target, histone-lysine $\mathrm{N}$-methyltransferase (EZH2), to inhibit self-renewal and clonogenic capacity in LNCaP, C4$2 \mathrm{~B}$, and PC-3 prostate cancer cell lines. The loss of let7 family was also found to be inversely correlated with increased expression of $\mathrm{EZH} 2$ in prostate cancer tissues compared to adjacent normal prostate tissues [59]. The expression of miR-146a was found to be lower in pancreatic cancer cells compared with normal human pancreatic duct epithelial cells. Treatment with DIM (which increased miR146a expression) or reexpression of miR-146a downregulated EGFR, interleukin 1 receptor-associated kinase 1 (IRAK-1), NF- $\kappa$ B and metastasis-associated protein, member 2 (MTA2), blocking cell invasion in Colo357 and Panc-1 pancreatic cancer cells [60].

6.2. miRNAs Targeting Tumour Suppressor Genes. The upregulation of miR-21, miR-31, miR-130a, miR-146b, and miR-377 observed in vinyl carbamate-induced lung cancer in mice was reversed by I3C. In addition, PTEN, PDCD4, and reversioninducing-cysteine-rich protein with Kazal motifs (RECK) were identified as potential targets of miR-21 [75]. In another study, it was demonstrated that I3C also downregulated miR21 in Panc-1 pancreatic carcinoma cells. Overexpression of miR-21 negated I3C-induced sensitivity towards gemcitabine and reduced the expression of its target, PDCD4, which was upregulated by I3C [76]. DIM was also found to downregulate miR-221 and upregulates its targets: PTEN, cyclindependent kinase inhibitor $1 \mathrm{~B}$ (p2 $\left.7^{\mathrm{kip} 1}\right)$, cyclin-dependent kinase inhibitor $1 \mathrm{C}$ ( $\left.\mathrm{p} 57^{\mathrm{kip} 2}\right)$, and $\mathrm{p} 53$ up-regulated modulator of apoptosis (PUMA), leading to suppression of cell proliferation and migration of MiaPaCa-2 and Panc- 1 pancreatic cancer cells. MiR-221 was significantly upregulated in pancreatic cancer cell lines and tumour tissues compared to normal pancreatic duct epithelial cells and tissues. Furthermore, patients with high expression of miR-221 had a relatively shorter survival compared to those with lower expression [77].

6.3. miRNAs Targeting Transcription Factors. The expression of miR-200b, miR-200c, let-7b, let-7c, let-7d, and let-7e was found to be downregulated in gemcitabine-resistant MiaPaCa-2 pancreatic cancer cells following treatment with DIM. The zinc finger E-box binding homeobox 1 (ZEB1), target of miR-200, was found to be downregulated following reexpression of miR-200. In addition, slug and vimentin were also downregulated, while E-cadherin was upregulated. These changes were consistent with phenotypic reversal of mesenchymal to epithelial morphology [83]. Besides that, DIM enhanced the effects of Herceptin when used in combination by inhibiting cell growth, colony formation, and inducing apoptosis in SKBR3 and MDA-MB-468 breast cancer cells through upregulation of miR-200. This combination treatment and overexpression of miR-200 resulted in downregulation of FoxM1, which has been implicated in progression of various cancers [113].

6.4. Other miRNAs. In another study, DIM downregulated miR-92a which is known to be associated with receptor activator of nuclear factor $-\kappa \mathrm{B}$ ligand (RANKL) signalling, EMT, and cancer progression to inhibit differentiation of osteoclasts and osteoblasts in prostate cancer metastasis [114].

\section{Other Natural Agents}

Ellagitannin (1,3-Di-O-galloyl-4,6-(s)-HHDP-b-D-glucopyranose), a polyphenolic compound isolated from $\mathrm{Bal}$ anophora japonica, was reported to upregulate $17 \mathrm{miR}$ NAs and downregulate 8 miRNAs in HepG2 hepatocellular 
carcinoma cells [115]. Another study reported that ursolic acid, a pentacyclic triterpene acid found in medicinal herbs such as Oldenlandia diffusa and Radix actinidiae, induced apoptosis in U251 glioblastoma cells by downregulating miR21 and inducing the expression of PDCD4, a target of miR21. Moreover, it was shown that overexpression of miR-21 suppressed the ursolic acid-induced expression of PDCD4 [116]. Garcinol, a polyisoprenylated benzophenone derivative obtained from Garcinia indica extracts, was found to reverse EMT in MDA-MB-231 and BT-549 breast cancer cells as well as in xenograft mouse model through upregulation of let-7a, let-7e, let-7f, miR-200b, and miR-200c. Additionally, it was also demonstrated that inhibition of miR-200a, miR-200b, and miR-200c attenuated the garcinol-mediated inhibition of invasion [117]. Besides that, matrine, an alkaloid isolated from Sophora flavescens, downregulated miR-21 to induce overexpression of PTEN and inactivate Akt, leading to cell cycle arrest and apoptosis in MCF-7 breast cancer cells [118]. Quercetin, a flavonoid found in onions, apples, tea, and red wine, upregulated miR-142-3p in pancreatic ductal adenocarcinoma cells (MIA PaCa-2, Capan-1, and S2-013). Overexpression of miR-142-3p inhibited cell proliferation and reduced the expression of its target, heat-shock protein 70 (HSP7). It was also shown that miR-143-3p regulated HSP70 expression independent of HSP1 and overexpression of HSP70 rescued miR-143-3p-induced cell death [119]. Furthermore, upregulation of miR-146a, a negative regulator of NF- $\kappa \mathrm{B}$ activation, by quercetin protected CCD-180Co colonic myofibroblast cells against ROS [120]. Recently, we have also reported that a total of 25 miRNAs were found to be significantly differentially expressed following treatment with $1^{\prime}$ S-1'-acetoxychavicol acetate (ACA), a natural compound isolated from the wild ginger, Alpinia conchigera, and/or cisplatin on Ca Ski and HeLa cervical carcinoma cells. These include miR-138, miR-210, and miR-744 with their predicted targets involved in signalling pathways regulating apoptosis and cell cycle progression [37]. Another study reported that ACA also downregulated miR-23a in HN4 head and neck squamous cells and its inhibition suppressed cell proliferation and induced apoptosis, with PTEN confirmed as its target [121]. Sulforaphane, an isothiocyanate derived from cruciferous vegetables such as broccoli and broccoli sprouts, upregulated 15 miRNAs (miR-372, miR-342-3p, miR-486-5p, miR9, miR-9*, miR-145, miR-146a, miR-629, miR-505, miR-758, miR-30a*, miR-27b*, miR-135b*, miR-27b, and miR-23b) and downregulated 3 miRNAs (miR-633, miR-155, and miR$106 \mathrm{a}^{*}$ ) in NCM460 and NCM356 normal colon epithelial cells [122]. In sulforaphane-treated T24 bladder cancer cells, miR-200c was found to be upregulated, leading to inhibition of EMT and metastasis. Downregulation and overexpression of miR-200c reversed and enhanced ZEB1 repression and E-cadherin induction by sulforaphane, respectively [123]. Besides that, miR-140 was found to be upregulated following sulforaphane treatment in MCF10DCIS and MDA-MB-231 breast cancer cells. Both SOX9 and aldehyde dehydrogenase 1 (ALDH1) were also identified as targets of miR-140, and miR140 overexpression downregulated the protein levels in both targets [124].

\section{Conclusion}

Based on current literature, it is increasingly evident that natural agents such as curcumin, resveratrol, genistein, EGCG, I3C, and DIM can alter miRNA expression profiles and target multiple genes at the same time. The pleiotropic effects of natural agents and miRNAs are attractive for cancer therapy since cancer is caused by defects in multiple genes. For this reason, it is proposed that natural agents can be used to downregulate oncogenic miRNAs and upregulate tumour suppressive miRNAs to restore drug sensitivity. Hence, there is a more promising role for natural agents in cancer therapies beyond their current use as chemopreventive agents and supplements. In conclusion, these natural agents which have been tested extensively in clinical trials and found to possess encouraging safety profiles can be used to simultaneously target diverse cellular signalling via specific miRNAs to serve as potential new avenues in cancer treatments. Together, it is hoped that these new strategies would prevent tumour recurrence and resistance towards conventional therapies, leading to improvement in the overall response and survival of cancer patients.

\section{Abbreviations}

\begin{tabular}{|c|c|}
\hline Ago2: & Argonaute2 \\
\hline Akt: & Protein kinase B \\
\hline Akt2: & Protein kinase $\mathrm{B} \beta$ \\
\hline ALDH1: & Aldehyde dehydrogenase 1 \\
\hline AP-1: & Activator protein-1 \\
\hline ARH1: & Aplysia ras homolog 1 \\
\hline ARHGDIA: & $\begin{array}{l}\text { Rho GDP dissociation inhibitor (GDI) } \\
\text { alpha }\end{array}$ \\
\hline BAD: & Bcl-2-associated death promoter \\
\hline BAX: & Bcl-2-associated X protein \\
\hline Bcl-2: & B-cell lymphoma 2 \\
\hline Bcl-xL: & B-cell lymphocyte xL \\
\hline CASZ1: & Castor zinc finger 1 \\
\hline Cdc25A: & Cell division cycle 25 homolog A \\
\hline C/EBP- $\beta$ : & CCAAT/enhancer binding protein beta \\
\hline CXCL: & Chemokine (C-X-C motif) \\
\hline DNMT3b: & DNA methyltransferase $3 \mathrm{~b}$ \\
\hline Dkk2: & Dickkopf 2 homolog \\
\hline eEF1A: & $\begin{array}{l}\text { Eukaryotic translation elongation factor } \\
1 \mathrm{~A}\end{array}$ \\
\hline EGFR: & Epidermal growth factor receptor \\
\hline EMT: & Epithelial-mesenchymal transition \\
\hline EP300: & E1A binding protein p300 \\
\hline Erbb3: & $\begin{array}{l}\text { Erythoblastic leukemia viral oncogene } \\
\text { homolog } 3\end{array}$ \\
\hline ESR1: & Estrogen receptor 1 \\
\hline Fbw7: & F-box and WD-40 domain protein 7 \\
\hline FOXC2: & Forkhead box C2 \\
\hline HIF- $1 \alpha$ : & Hypoxia-inducible factor $1 \alpha$ \\
\hline HOTAIR: & HOX transcript antisense RNA \\
\hline HSP70: & Heat-shock protein 70 \\
\hline IL1RAPL1: & $\begin{array}{l}\text { Interleukin } 1 \text { receptor accessory } \\
\text { protein-like } 1\end{array}$ \\
\hline IRAK & Interleukin 1 receptor-associated \\
\hline
\end{tabular}


K-Ras: Kirsten rat sarcoma viral oncogene homolog

MAPK: Mitogen-activated protein kinase

MCM: Minichromosome maintenance

MMP: $\quad$ Matrix metalloproteinases

MTA2: Metastasis-associated protein, member 2

N4BP1: NEDD4 binding protein 1

NF- $\kappa$ B: $\quad$ Nuclear factor-kappa B

p27 $7^{\text {kipl }}$ : Cyclin-dependent kinase inhibitor $1 \mathrm{~B}$

p57 ${ }^{\text {kip2 }}$ : Cyclin-dependent kinase inhibitor $1 \mathrm{C}$

PARP: $\quad$ Poly ADP ribose polymerase

PDCD4: Programmed cell death protein 4

PPAR: Peroxisome proliferator-activated receptor

PTEN: Phosphatase and tensin homologue deleted on chromosome 10

PSA: $\quad$ Prostate specific antigen

PUMA: p53 upregulated modulator of apoptosis

RAC1: $\quad$ Ras-related C3 botulinum toxin substrate 1

RANKL: Receptor activator of nuclear factor $-\kappa B$ ligand

RECK: Reversion-inducing-cysteine-rich protein with Kazal motifs

ROS: $\quad$ Reactive oxygen species

sFRP1: Wnt-signalling secreted frizzled-related protein 1

Sirtl: $\quad$ Sirtuin (silent mating type information regulation 2 homolog) 1

SMAD: Mothers against decapentaplegic

Sp: $\quad$ Specificity protein

Src: V-src avian sarcoma viral oncogene homolog

SOX17: $\quad$ SRY (sex determining region Y)-box 17

TGF $\beta$ : Transforming growth factor beta

TNFSF10: Tumour necrosis factor (ligand) superfamily, member 10

WT1: Wilm's tumour 1

ZBTB: Zinc finger and BTB domain-containing protein

ZEB1: $\quad$ Zinc finger E-box binding homeobox 1.

\section{Conflict of Interests}

The authors declared that there is no conflict of interests regarding the publication of this paper.

\section{Acknowledgments}

This work was supported by the University of Malaya Research Grant (UMRG) (RP001B-13BIO) and University of Malaya Postgraduate Research Fund (PPP) (PV058-2011B). All funders had no role in decision to publish or in preparation of the paper.

\section{References}

[1] J. Ferlay, I. Soerjomataram, M. Ervik et al., "GLOBOCAN 2012 v1.0, Cancer Incidence and Mortality Worldwide: IARC CancerBase No. 11," http://globocan.iarc.fr.
[2] M. M. Gottesman, "Mechanisms of cancer drug resistance," Annual Review of Medicine, vol. 53, pp. 615-627, 2002.

[3] J. H. Goldie, "Drug resistance in cancer: a perspective," Cancer and Metastasis Reviews, vol. 20, no. 1-2, pp. 63-68, 2001.

[4] Y. Li, D. Kong, Z. Wang, and F. H. Sarkar, "Regulation of microRNAs by natural agents: an emerging field in chemoprevention and chemotherapy research," Pharmaceutical Research, vol. 27, no. 6, pp. 1027-1041, 2010.

[5] A. Bhanot, R. Sharma, and M. N. Noolvi, "Natural sources as potential anti-cancer agents: a review," International Journal of Phytomedicine, vol. 3, no. 1, pp. 9-26, 2011.

[6] N. Hasima and B. B. Aggarwal, "Cancer-linked targets modulated by curcumin," International Journal of Biochemistry and Molecular Biology, vol. 3, no. 4, pp. 328-351, 2012.

[7] A. Borriello, D. Bencivenga, I. Caldarelli et al., "Resveratrol: from basic studies to bedside," Cancer Treatment and Research, vol. 159, pp. 167-184, 2014.

[8] C. K. Singh, J. George, and N. Ahmad, "Resveratrol-based combinatorial strategies for cancer management," Annals of the New York Academy of Sciences, vol. 1290, no. 1, pp. 113-121, 2013.

[9] H. Q. Li, Y. Luo, and C. H. Qiao, "The mechanisms of anticancer agents by genistein and synthetic derivatives of isoflavone," Mini-Reviews in Medicinal Chemistry, vol. 12, no. 4, pp. 350-362, 2012.

[10] Y. Shirakami, M. Shimizu, and H. Moriwaki, "Cancer chemoprevention with green tea catechins: from bench to bed," Current Drug Targets, vol. 13, no. 14, pp. 1842-1857, 2012.

[11] A. Acharya, I. Das, S. Singh, and T. Saha, "Chemopreventive properties of indole-3-carbinol, diindolylmethane and other constituents of cardamom against carcinogenesis," Recent Patents on Food, Nutrition and Agriculture, vol. 2, no. 2, pp. 166177, 2010.

[12] J. Weng, H. A. Omar, S. K. Kulp, and C. Chen, "Pharmacological exploitation of indole-3-carbinol to develop potent antitumor agents," Mini Reviews in Medicinal Chemistry, vol. 10, no. 5, pp. 398-404, 2010.

[13] C. S. Yang, J. M. Landau, M.-. Huang, and H. L. Newmark, "Inhibition of carcinogenesis by dietary polyphenolic compounds," Annual Review of Nutrition, vol. 21, pp. 381-406, 2001.

[14] B. B. Aggarwal and S. Shishodia, "Molecular targets of dietary agents for prevention and therapy of cancer," Biochemical Pharmacology, vol. 71, no. 10, pp. 1397-1421, 2006.

[15] M. Lagos-Quintana, R. Rauhut, W. Lendeckel, and T. Tuschl, "Identification of novel genes coding for small expressed RNAs," Science, vol. 294, no. 5543, pp. 853-858, 2001.

[16] R. C. Friedman, K. K. Farh, C. B. Burge, and D. P. Bartel, "Most mammalian mRNAs are conserved targets of microRNAs," Genome Research, vol. 19, no. 1, pp. 92-105, 2009.

[17] L. P. Lim, N. C. Lau, E. G. Weinstein et al., "The microRNAs of Caenorhabditis elegans," Genes and Development, vol. 17, no. 8, pp. 991-1008, 2003.

[18] Y. Lee, M. Kim, J. Han et al., "MicroRNA genes are transcribed by RNA polymerase II," The EMBO Journal, vol. 23, no. 20, pp. 4051-4060, 2004.

[19] A. M. Denli, B. B. J. Tops, R. H. A. Plasterk, R. F. Ketting, and G. J. Hannon, "Processing of primary microRNAs by the Microprocessor complex," Nature, vol. 432, no. 7014, pp. 231235, 2004.

[20] M. T. Bohnsack, K. Czaplinski, and D. Görlich, "Exportin 5 is a RanGTP-dependent dsRNA-binding protein that mediates nuclear export of pre-miRNAs," RNA, vol. 10, no. 2, pp. 185-191, 2004. 
[21] J. Winter, S. Jung, S. Keller, R. I. Gregory, and S. Diederichs, "Many roads to maturity: microRNA biogenesis pathways and their regulation," Nature Cell Biology, vol. 11, no. 3, pp. 228-234, 2009.

[22] S. M. Hammond, E. Bernstein, D. Beach, and G. J. Hannon, "An RNA-directed nuclease mediates post-transcriptional gene silencing in Drosophila cells," Nature, vol. 404, no. 6775, pp. 293-296, 2000.

[23] Z. Fang and N. Rajewsky, "The impact of miRNA target sites in coding sequences and in $3^{\prime}$ UTRs," PLoS ONE, vol. 6, no. 3, Article ID e18067, 2011.

[24] J. R. Lytle, T. A. Yario, and J. A. Steitz, "Target mRNAs are repressed as efficiently by microRNA-binding sites in the 5/UTR as in the $3^{\prime}$ UTR,' Proceedings of the National Academy of Sciences of the United States of America, vol. 104, no. 23, pp. 9667-9672, 2007.

[25] S. Vasudevan, Y. Tong, and J. A. Steitz, "Switching from repression to activation: microRNAs can up-regulate translation," Science, vol. 318, no. 5858, pp. 1931-1934, 2007.

[26] A. M. Eiring, J. G. Harb, P. Neviani et al., "miR-328 functions as an RNA decoy to modulate hnRNP E2 regulation of mRNA translation in leukemic blasts," Cell, vol. 140, no. 5, pp. 652-665, 2010.

[27] S. Wu, S. Huang, J. Ding et al., "Multiple microRNAs modulate p21Cip1/Wafl expression by directly targeting its 3 ' untranslated region," Oncogene, vol. 29, no. 15, pp. 2302-2308, 2010.

[28] G. A. Calin and C. M. Croce, "MicroRNA signatures in human cancers," Nature Reviews Cancer, vol. 6, no. 11, pp. 857-866, 2006.

[29] E. A. C. Wiemer, "The role of microRNAs in cancer: no small matter," European Journal of Cancer, vol. 43, no. 10, pp. 15291544, 2007.

[30] J. K. Palanichamy and D. S. Rao, "miRNA dysregulation in cancer: towards a mechanistic understanding," Frontiers in Genetics, vol. 5, article 54, 2014.

[31] J. M. Bouyssou, S. Manier, D. Huynh, S. Issa, A. M. Roccaro, and I. M. Ghobrial, "Regulation of microRNAs in cancer metastasis," Biochim Biophys Acta, vol. 22, no. 1845, pp. 255-265, 2014.

[32] G. di Leva, M. Garofalo, and C. M. Croce, "MicroRNAs in cancer," Annual Review of Pathology, vol. 9, pp. 287-314, 2014.

[33] H. Ling, M. Fabbri, and G. A. Calin, "MicroRNAs and other non-coding RNAs as targets for anticancer drug development," Nature Reviews Drug Discovery, vol. 12, no. 11, pp. 847-865, 2013.

[34] R. Titone, F. Morani, C. Follo, C. Vidoni, D. Mezzanzanica, and C. Isidoro, "Epigenetic control of autophagy by MicroRNAs in ovarian cancer," BioMed Research International, vol. 2014, Article ID 343542, 11 pages, 2014.

[35] S. Tan, Y. Wu, C. Y. Zhang, and J. Li, "Potential microRNA targets for cancer chemotherapy," Current Medicinal Chemistry, vol. 20, no. 29, pp. 574-581, 2013.

[36] K. Banno, M. Yanokura, M. Iida et al., "Application of microRNA in diagnosis and treatment of ovarian cancer," BioMed Research International, vol. 2014, Article ID 232817, 6 pages, 2014.

[37] N. H. Phuah, L. L. A. In, M. N. Azmi, H. Ibrahim, K. Awang, and N. H. Nagoor, "Alterations of MicroRNA expression patterns in human cervical carcinoma cells (Ca Ski) toward 1/S-1/acetoxychavicol acetate and cisplatin," Reproductive Sciences, vol. 20, no. 5, pp. 567-578, 2013.
[38] D. Karunagaran, J. Joseph, and T. R. Kumar, "Cell growth regulation," Advances in Experimental Medicine and Biology, vol. 595, pp. 245-268, 2007.

[39] S. C. Gupta, J. H. Kim, S. Prasad, and B. B. Aggarwal, "Regulation of survival, proliferation, invasion, angiogenesis, and metastasis of tumor cells through modulation of inflammatory pathways by nutraceuticals," Cancer and Metastasis Reviews, vol. 29, no. 3, pp. 405-434, 2010.

[40] D. Karunagaran, R. Rashmi, and T. R. Kumar, "Induction of apoptosis by curcumin and its implications for cancer therapy," Current Cancer Drug Targets, vol. 5, no. 2, pp. 117-129, 2005.

[41] E. Kronski, M. E. Fiori, O. Barbieri et al., "miR181b is induced by the chemopreventive polyphenol curcumin and inhibits breast cancer metastasis via down-regulation of the inflammatory cytokines CXCL1 and -2," Molecular Oncology, vol. 8, no. 3, pp. 581-595, 2014.

[42] J. Yang, Y. Cao, J. Sun, and Y. Zhang, "Curcumin reduces the expression of Bcl-2 by upregulating miR-15a and miR-16 in MCF-7 cells," Medical Oncology, vol. 27, no. 4, pp. 1114-1118, 2010.

[43] S. Gao, J. Yang, C. Chen et al., "Pure curcumin decreases the expression of WT1 by upregulation of miR-15a and miR-16-1 in leukemic cells," Journal of Experimental \& Clinical Cancer Research, vol. 31, no. 1, article 27, 2012.

[44] S. Saini, S. Arora, S. Majid et al., "Curcumin modulates microRNA-203-mediated regulation of the Src-Akt axis in bladder cancer," Cancer Prevention Research, vol. 4, no. 10, pp. 1698-1709, 2011.

[45] S. Sreenivasan, K. Thirumalai, R. Danda, and S. Krishnakumar, "Effect of curcumin on miRNA expression in human Y79 retinoblastoma cells," Current Eye Research, vol. 37, no. 5, pp. 421-428, 2012.

[46] J. Zhang, Y. Du, C. Wu et al., "Curcumin promotes apoptosis in human lung adenocarcinoma cells through miR-186* signaling pathway," Oncology Reports, vol. 24, no. 5, pp. 1217-1223, 2010.

[47] J. Zhang, T. Zhang, X. Ti et al., "Curcumin promotes apoptosis in A549/DDP multidrug-resistant human lung adenocarcinoma cells through an miRNA signaling pathway," Biochemical and Biophysical Research Communications, vol. 399, no. 1, pp. 16, 2010.

[48] G. Mudduluru, J. N. George-William, S. Muppala et al., "Curcumin regulates miR-21 expression and inhibits invasion and metastasis in colorectal cancer," Bioscience Reports, vol. 31, no. 3, pp. 185-197, 2011.

[49] D. Subramaniam, S. Ponnurangam, P. Ramamoorthy et al., "Curcumin induces cell death in esophageal cancer cells through modulating Notch signaling," PLoS ONE, vol. 7, no. 2, Article ID e30590, 2012.

[50] H. H. Liang, P. L. Wei, C. S. Hung et al., "MicroRNA-200a/b influenced the therapeutic effects of curcumin in hepatocellular carcinoma (HCC) cells," Tumor Biology, vol. 34, no. 5, pp. 3209$3218,2013$.

[51] A. Vislovukh, G. Kratassiouk, E. Porto et al., "Proto-oncogenic isoform A2 of eukaryotic translation elongation factor eEF1 is a target of miR-663 and miR-744," The British Journal of Cancer, vol. 108, no. 11, pp. 2304-2311, 2013.

[52] P. Liu, H. Liang, Q. Xia et al., "Resveratrol induces apoptosis of pancreatic cancers cells by inhibiting miR-21 regulation of BCL2 expression," Clinical and Translational Oncology, vol. 15, no. 9, pp. 741-746, 2013.

[53] Z. Han, Q. Yang, B. Liu et al., "MicroRNA-622 functions as a tumor suppressor by targeting K-Ras and enhancing the 
anticarcinogenic effect of resveratrol," Carcinogenesis, vol. 33, no. 1, pp. 131-139, 2012.

[54] T. Chiyomaru, S. Yamamura, S. Fukuhara et al., "Genistein inhibits prostate cancer cell growth by targeting miR-34a and oncogenic HOTAIR," PLoS ONE, vol. 8, no. 8, Article ID e70372, 2013.

[55] T. Chiyomaru, S. Yamamura, S. Fukuhara et al., "Genistein up-regulates tumor suppressor microRNA-574-3p in prostate cancer," PLoS ONE, vol. 8, no. 3, Article ID e58929, 2013.

[56] S. Majid, A. A. Dar, S. Saini et al., "Regulation of minichromosome maintenance gene family by MicroRNA-1296 and genistein in prostate cancer," Cancer Research, vol. 70, no. 7, pp. 2809-2818, 2010.

[57] W. P. Tsang and T. T. Kwok, "Epigallocatechin gallate upregulation of miR-16 and induction of apoptosis in human cancer cells," Journal of Nutritional Biochemistry, vol. 21, no. 2, pp. 140-146, 2010.

[58] Y. Jin, “3,3'-Diindolylmethane inhibits breast cancer cell growth via miR-21-mediated Cdc25A degradation.", Molecular and Cellular Biochemistry, vol. 358, no. 1-2, pp. 345-354, 2011.

[59] D. Kong, E. Heath, W. Chen et al., "Loss of let-7 up-regulates EZH2 in prostate cancer consistent with the acquisition of cancer stem cell signatures that are attenuated by BR-DIM," PLoS ONE, vol. 7, no. 3, Article ID e33729, 2012.

[60] Y. Li, T. G. VandenBoom II, Z. Wang et al., "miR-146a suppresses invasion of pancreatic cancer cells," Cancer Research, vol. 70, no. 4, pp. 1486-1495, 2010.

[61] E. Tili, J. Michaille, H. Alder et al., "Resveratrol modulates the levels of microRNAs targeting genes encoding tumorsuppressors and effectors of TGF $\beta$ signaling pathway in SW480 cells," Biochemical Pharmacology, vol. 80, no. 12, pp. 2057-2065, 2010.

[62] S. Dhar, C. Hicks, and A. S. Levenson, "Resveratrol and prostate cancer: promising role for microRNAs," Molecular Nutrition \& Food Research, vol. 55, no. 8, pp. 1219-1229, 2011.

[63] S. Sheth, S. Jajoo, T. Kaur et al., "Resveratrol reduces prostate cancer growth and metastasis by inhibiting the Akt/MicroRNA21 pathway," PLoS ONE, vol. 7, no. 12, Article ID e51655, 2012.

[64] Z. Cao, J. H. Yoon, S. W. Nam, J. Y. Lee, and W. S. Park, "PDCD4 expression inversely correlated with miR-21 levels in gastric cancers," Journal of Cancer Research and Clinical Oncology, vol. 138, no. 4, pp. 611-619, 2012.

[65] Y. Chen, M. S. Zaman, G. Deng et al., "MicroRNAs 221/222 and genistein-mediated regulation of ARHI tumor suppressor gene in prostate cancer," Cancer Prevention Research, vol. 4, no. 1, pp. 76-86, 2011.

[66] T. Chiyomaru, S. Yamamura, M. S. Zaman et al., "Genistein suppresses prostate cancer growth through inhibition of oncogenic MicroRNA-151," PLoS ONE, vol. 7, no. 8, Article ID e43812, 2012.

[67] M. S. Zaman, S. Thamminana, V. Shahryari et al., "Inhibition of PTEN gene expression by oncogenic miR-23b-3p in renal cancer," PLoS ONE, vol. 7, no. 11, Article ID e50203, 2012.

[68] H. Hirata, K. Ueno, K. Nakajima et al., "Genistein downregulates onco-miR-1260b and inhibits Wnt-signalling in renal cancer cells," British Journal of Cancer, vol. 108, no. 10, pp. 20702078, 2013.

[69] H. Hirata, Y. Hinoda, V. Shahryari et al., "Genistein downregulates onco-miR-1260b and upregulates sFRP1 and Smad4 via demethylation and histone modification in prostate cancer cells," British Journal of Cancer, vol. 110, no. 6, pp. 1645-1654, 2014.
[70] J. Ma, L. Cheng, H. Liu et al., "Genistein down-regulates miR223 expression in pancreatic cancer cells," Current Drug Targets, vol. 14, no. 10, pp. 1150-1156, 2013.

[71] Q. Sun, R. Cong, H. Yan et al., "Genistein inhibits growth of human uveal melanoma cells and affects microRNA-27a and target gene expression," Oncology Reports, vol. 22, no. 3, pp. 563$567,2009$.

[72] L. Xu, J. Xiang, J. Shen et al., "Oncogenic microrna-27a is a target for genistein in ovarian cancer cells," Anti-Cancer Agents in Medicinal Chemistry, vol. 13, no. 7, pp. 1126-1132, 2013.

[73] J. Xia, L. Cheng, C. Mei et al., "Genistein inhibits cell growth and invasion through regulation of miR-27a in pancreatic cancer cells," Current Pharmaceutical Design, 2014.

[74] D. H. Zhou, X. Wang, and Q. Feng, "EGCG enhances the efficacy of cisplatin by downregulating hsa-miR-98-5p in NSCLC A549 cells," Nutrition and Cancer, vol. 66, no. 4, pp. 636-644, 2014.

[75] T. Melkamu, X. Zhang, J. Tan, Y. Zeng, and F. Kassie, "Alteration of microRNA expression in vinyl carbamate-induced mouse lung tumors and modulation by the chemopreventive agent indole-3-carbinol," Carcinogenesis, vol. 31, no. 2, pp. 252-258, 2010.

[76] W. H. Paik, H. R. Kim, J. K. Park, B. J. Song, S. H. Lee, and J. Hwang, "Chemosensitivity induced by down-regulation of MicroRNA-21 in gemcitabine-resistant pancreatic cancer cells by indole-3-carbinol," Anticancer Research, vol. 33, no. 4, pp. 1473-1482, 2013.

[77] S. Sarkar, H. Dubaybo, S. Ali et al., "Down-regulation of miR221 inhibits proliferation of pancreatic cancer cells through up-regulation of PTEN, p27(kip1), p57(kip2), and PUMA," American Journal of Cancer Research, vol. 3, no. 5, pp. 465-477, 2013.

[78] M. Sun, Z. Estrov, Y. Ji, K. R. Coombes, D. H. Harris, and R. Kurzrock, "Curcumin (diferuloylmethane) alters the expression profiles of microRNAs in human pancreatic cancer cells," Molecular Cancer Therapeutics, vol. 7, no. 3, pp. 464-473, 2008.

[79] S. U. Gandhy, K. Kim, L. Larsen, R. J. Rosengren, and S. Safe, "Curcumin and synthetic analogs induce reactive oxygen species and decreases specificity protein (sp) transcription factors by targeting MicroRNAs," BMC Cancer, vol. 12, p. 564, 2012.

[80] M. Kumazaki, S. Noguchi, Y. Yasui et al., "Anti-cancer effects of naturally occurring compounds through modulation of signal transduction and miRNA expression in human colon cancer cells," Journal of Nutritional Biochemistry, vol. 24, no. 11, pp. 1849-1858, 2013.

[81] Y. H. Yu, H. A. Chen, P. S. Chen, and et al, "MiR-520hmediated FOXC2 regulation is critical for inhibition of lung cancer progression by resveratrol," Oncogene, vol. 32, no. 4, pp. 431-443, 2013.

[82] E. Tili, J. Michaille, B. Adair et al., "Resveratrol decreases the levels of miR-155 by upregulating miR-663, a microRNA targeting JunB and JunD," Carcinogenesis, vol. 31, no. 9, pp. 15611566, 2010.

[83] Y. Li, T. G. Vandenboom II, D. Kong et al., "Up-regulation of miR-200 and let-7 by natural agents leads to the reversal of epithelial-to-mesenchymal transition in gemcitabine-resistant pancreatic cancer cells," Cancer Research, vol. 69, no. 16, pp. 6704-6712, 2009.

[84] F. Holst, P. R. Stahl, C. Ruiz et al., "Estrogen receptor alpha (ESR1) gene amplification is frequent in breast cancer," Nature Genetics, vol. 39, no. 5, pp. 655-660, 2007. 
[85] B. S. Katzenellenbogen, K. L. Kendra, M. J. Norman, and Y. Berthois, "Proliferation, hormonal responsiveness, and estrogen receptor content of MCF-7 human breast cancer cells grown in the short-term and long-term absence of estrogens," Cancer Research, vol. 47, no. 16, pp. 4355-4360, 1987.

[86] S. Safe and M. Abdelrahim, "Sp transcription factor family and its role in cancer," European Journal of Cancer, vol. 41, no. 16, pp. 2438-2448, 2005.

[87] M. Abdelrahim, C. H. Baker, J. L. Abbruzzese et al., "Regulation of vascular endothelial growth factor receptor-1 expression by specificity proteins 1,3 , and 4 in pancreatic cancer cells," Cancer Research, vol. 67, no. 7, pp. 3286-3294, 2007.

[88] G. Chadalapaka, I. Jutooru, S. Chintharlapalli et al., "Curcumin decreases specificity protein expression in bladder cancer cells," Cancer Research, vol. 68, no. 13, pp. 5345-5354, 2008.

[89] N. C. Whitlock and S. J. Baek, "The anticancer effects of resveratrol: modulation of transcription factors," Nutrition and Cancer, vol. 64, no. 4, pp. 493-502, 2012.

[90] A. del Follo-Martinez, N. Banerjee, X. Li, S. Safe, and S. Mertens-Talcott, "Resveratrol and quercetin in combination have anticancer activity in colon cancer cells and repress oncogenic microRNA-27a," Nutrition and Cancer, vol. 65, no. 3, pp. 494-504, 2013.

[91] E. Tili, C. M. Croce, and J. Michaille, "MiR-155: On the crosstalk between inflammation and cancer," International Reviews of Immunology, vol. 28, no. 5, pp. 264-284, 2009.

[92] S. Bae, E. Lee, H. J. Cha et al., "Resveratrol alters microRNA expression profiles in A549 human non-small cell lung cancer cells," Molecules and Cells, vol. 32, no. 3, pp. 243-249, 2011.

[93] K. Hagiwara, N. Kosaka, Y. Yoshioka, R. Takahashi, F. Takeshita, and T. Ochiya, "Stilbene derivatives promote Ago2-dependent tumour-suppressive microRNA activity," Scientific Reports, vol. 2, article 314, 2012.

[94] M. Sachdeva, Q. Liu, J. Cao, Z. Lu, and Y. Mo, "Negative regulation of miR-145 by C/EBP- $\beta$ through the Akt pathway in cancer cells," Nucleic Acids Research, vol. 40, no. 14, pp. 66836692, 2012.

[95] W. Qin, K. Zhang, K. Clarke, T. Weiland, and E. R. Sauter, "Methylation and miRNA effects of resveratrol on mammary tumors vs. normal tissue," Nutrition and Cancer, vol. 66, no. 2, pp. 270-277, 2014.

[96] P. B. Kaufman, J. A. Duke, H. Brielmann, J. Boik, and J. E. Hoyt, "A comparative survey of leguminous plants as sources of the isoflavones, genistein and daidzein: implications for human nutrition and health," Journal of Alternative and Complementary Medicine, vol. 3, no. 1, pp. 7-12, 1997.

[97] S. Banerjee, Y. Li, Z. Wang, and F. H. Sarkar, "Multi-targeted therapy of cancer by genistein," Cancer Letters, vol. 269, no. 2, pp. 226-242, 2008.

[98] M. S. Zaman, Y. Chen, G. Deng et al., "The functional significance of microRNA-145 in prostate cancer," The British Journal of Cancer, vol. 103, no. 2, pp. 256-264, 2010.

[99] N. Rabiau, H. Trraf, M. Adjakly et al., "miRNAs differentially expressed in prostate cancer cell lines after soy treatment," In Vivo, vol. 25, no. 6, pp. 917-921, 2011.

[100] M. S. Zaman, V. Shahryari, G. Deng et al., "Up-regulation of microRNA-21 correlates with lower kidney cancer survival," PLoS ONE, vol. 7, no. 2, Article ID e31060, 2012.

[101] J. Xia, Q. Duan, A. Ahmad et al., "Genistein inhibits cell growth and induces apoptosis through Up-regulation of miR-34a in pancreatic cancer cells," Current Drug Targets, vol. 13, no. 14, pp. 1750-1756, 2012.
[102] N. Khan, F. Afaq, M. Saleem, N. Ahmad, and H. Mukhtar, "Targeting multiple signaling pathways by green tea polyphenol (-)-epigallocatechin-3-gallate," Cancer Research, vol. 66, no. 5, pp. 2500-2505, 2006.

[103] C. S. Yang, X. Wang, G. Lu, and S. C. Picinich, "Cancer prevention by tea: animal studies, molecular mechanisms and human relevance," Nature Reviews Cancer, vol. 9, no. 6, pp. 429439, 2009.

[104] A. Arola-Arnal and C. Bladé, "Proanthocyanidins modulate microRNA expression in human HepG2 cells," PLoS ONE, vol. 6, no. 10, Article ID e25982, 2011.

[105] H. Wang, S. Bian, and C. S. Yang, "Green tea polyphenol EGCG suppresses lung cancer cell growth through upregulating miR210 expression caused by stabilizing HIF- $1 \alpha$," Carcinogenesis, vol. 32, no. 12, Article ID bgr218, pp. 1881-1889, 2011.

[106] M. Chakrabarti, M. Khandkar, N. L. Banik, and S. K. Ray, "Alterations in expression of specific microRNAs by combination of 4-HPR and EGCG inhibited growth of human malignant neuroblastoma cells," Brain Research, vol. 1454, pp. 1-13, 2012.

[107] C. P. Reynolds, D. J. Kane, P. A. Einhorn et al., "Response of neuroblastoma to retinoic acid in vitro and in vivo," Progress in Clinical and Biological Research, vol. 366, pp. 203-211, 1991.

[108] M. Chakrabarti, W. Ai, N. L. Banik, and S. K. Ray, "Overexpression of miR-7-1 increases efficacy of green tea polyphenols for induction of apoptosis in human malignant neuroblastoma SHSY5Y and SK-N-DZ cells," Neurochemical Research, vol. 38, no. 2, pp. 420-432, 2013.

[109] I. A. Siddiqui, M. Asim, B. B. Hafeez, V. M. Adhami, R. S. Tarapore, and H. Mukhtar, "Green tea polyphenol EGCG blunts androgen receptor function in prostate cancer," The FASEB Journal, vol. 25, no. 4, pp. 1198-1207, 2011.

[110] M. J. Anderton, M. M. Manson, R. D. Verschoyle et al., "Pharmacokinetics and tissue disposition of indole-3-carbinol and its acid condensation products after oral administration to mice," Clinical Cancer Research, vol. 10, no. 15, pp. 5233-5241, 2004.

[111] Y. Li, X. Li, and F. H. Sarkar, "Gene expression profiles of $\mathrm{I}_{3} \mathrm{C}$ and DIM-treated $\mathrm{PC}_{3}$ human prostate cancer cells determined by cDNA microarray analysis," Journal of Nutrition, vol. 133, no. 4, pp. 1011-1019, 2003.

[112] F. H. Sarkar and Y. Li, "Indole-3-carbinol and prostate cancer," Journal of Nutrition, vol. 134, no. 12, pp. 3493S-3498S, 2004.

[113] A. Ahmad, S. Ali, A. Ahmed et al., “3, 3'-Diindolylmethane enhances the effectiveness of herceptin against HER-2/neuexpressing breast cancer cells," PLoS ONE, vol. 8, no. 1, Article ID e54657, 2013.

[114] Y. Li, D. Kong, A. Ahmad, B. Bao, and F. H. Sarkar, “Targeting bone remodeling by isoflavone and $3,3^{\prime}$-diindolylmethane in the context of prostate cancer bone metastasis," PLOS ONE, vol. 7, no. 3, Article ID e33011, 2012.

[115] X. Y. Wen, S. Y. Wu, Z. Q. Li et al., "Ellagitannin (BJA3121), an anti-proliferative natural polyphenol compound, can regulate the expression of MiRNAs in HepG2 cancer cells," Phytotherapy Research, vol. 23, no. 6, pp. 778-784, 2009.

[116] J. Wang, Y. Li, X. Wang, and C. Jiang, "Ursolic Acid Inhibits Proliferation and Induces Apoptosis in Human Glioblastoma Cell Lines U251 by Suppressing TGF- $\beta 1 /$ miR-21/PDCD4 Pathway," Basic \& Clinical Pharmacology \& Toxicology, vol. 111, no. 2, pp. 106-112, 2012.

[117] A. Ahmad, S. H. Sarkar, B. Bitar et al., "Garcinol regulates EMT and Wnt signaling pathways in vitro and in vivo, leading to 
anticancer activity against breast cancer cells," Molecular Cancer Therapeutics, vol. 11, no. 10, pp. 2193-2201, 2012.

[118] L. Q. Li, X. L. Li, L. Wang et al., "Matrine inhibits breast cancer growth via miR-21/PTEN/Akt pathway in MCF-7 cells," Cellular Physiology and Biochemistry, vol. 30, no. 3, pp. 631-641, 2012.

[119] T. N. MacKenzie, N. Mujumdar, S. Banerjee et al., "Triptolide induces the expression of miR-142-3p: a negative regulator of heat shock protein 70 and pancreatic cancer cell proliferation," Molecular Cancer Therapeutics, vol. 12, no. 7, pp. 1266-1275, 2013.

[120] G. D. Noratto, Y. Kim, S. T. Talcott, and S. U. MertensTalcott, "Flavonol-rich fractions of yaupon holly leaves (Ilex vomitoria, Aquifoliaceae) induce microRNA-146a and have anti-inflammatory and chemopreventive effects in intestinal myofribroblast CCD-18Co cells," Fitoterapia, vol. 82, no. 4, pp. 557-569, 2011.

[121] H. Wang, L. Shen, X. Li, and M. Sun, "MicroRNAs contribute to the anticancer effect of $1^{\prime}$-acetoxychavicol acetate in human head and neck squamous cell carcinoma cell line HN4," Bioscience, Biotechnology, and Biochemistry, vol. 77, no. 12, pp. 2348-2355, 2013.

[122] O. Slaby, M. Sachlova, V. Brezkova et al., "Identification of microRNAs regulated by isothiocyanates and association of polymorphisms inside their target sites with risk of sporadic colorectal cancer," Nutrition and Cancer, vol. 65, no. 2, pp. 247254, 2013.

[123] Y. Shan, L. Zhang, Y. Bao et al., "Epithelial-mesenchymal transition, a novel target of sulforaphane via COX-2/MMP2, 9/Snail, ZEB1 and miR-200c/ZEB1 pathways in human bladder cancer cells," Journal of Nutritional Biochemistry, vol. 24, no. 6, pp. 1062-1069, 2013.

[124] Q. Li, Y. Yao, G. Eades, Z. Liu, Y. Zhang, and Q. Zhou, “Downregulation of miR-140 promotes cancer stem cell formation in basal-like early stage breast cancer," Oncogene, vol. 33, no. 20, pp. 2589-2600, 2014. 

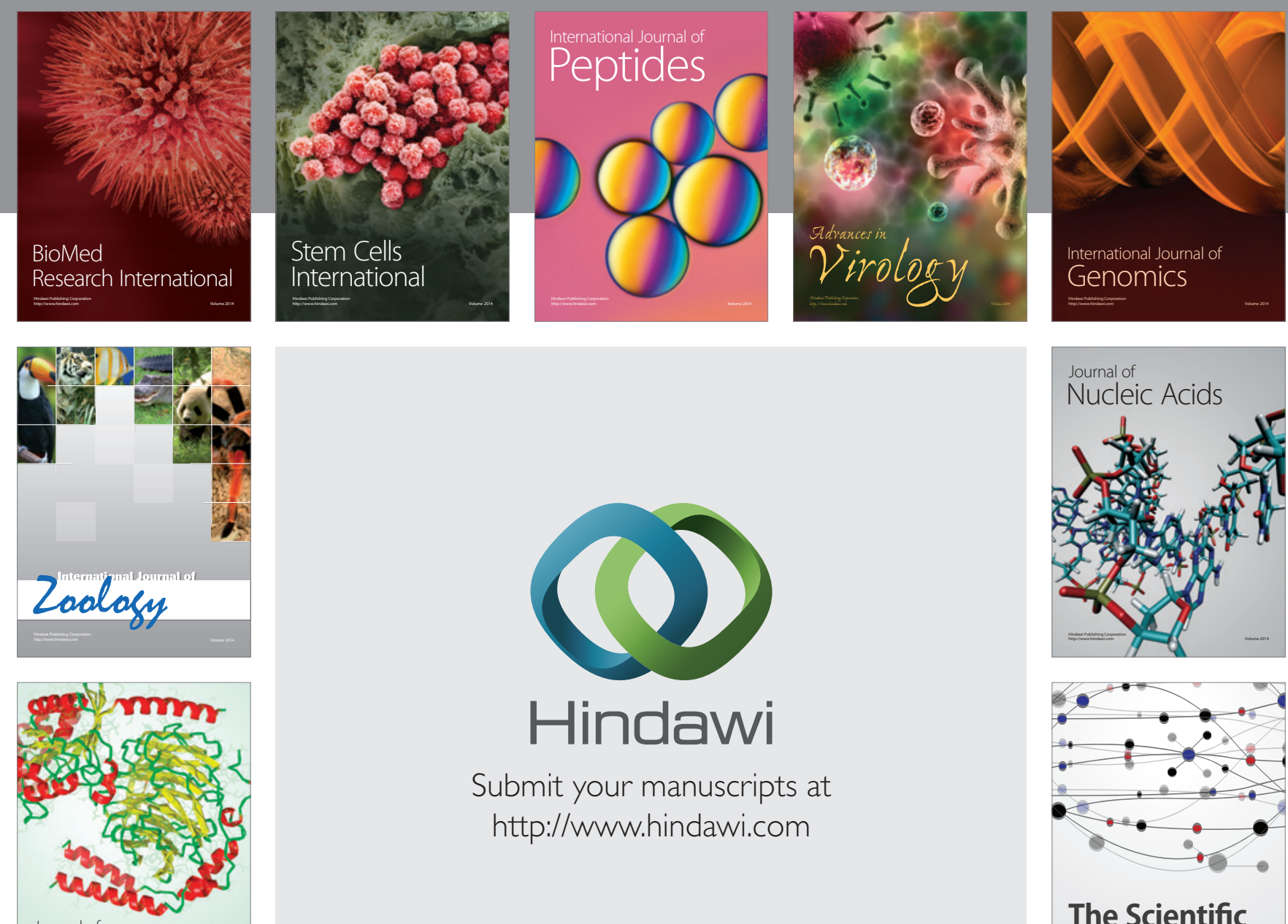

Submit your manuscripts at

http://www.hindawi.com

Journal of
Signal Transduction
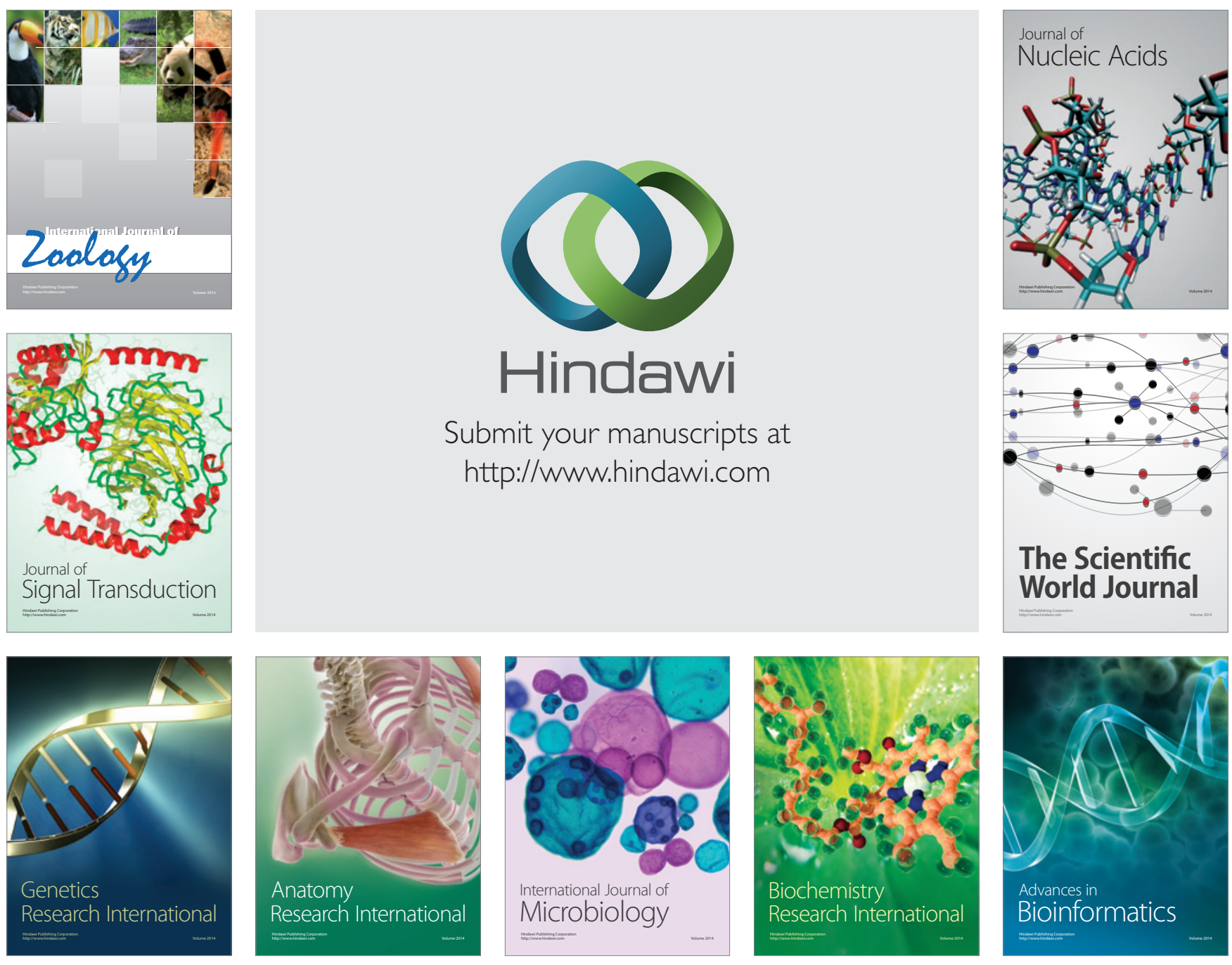

The Scientific World Journal
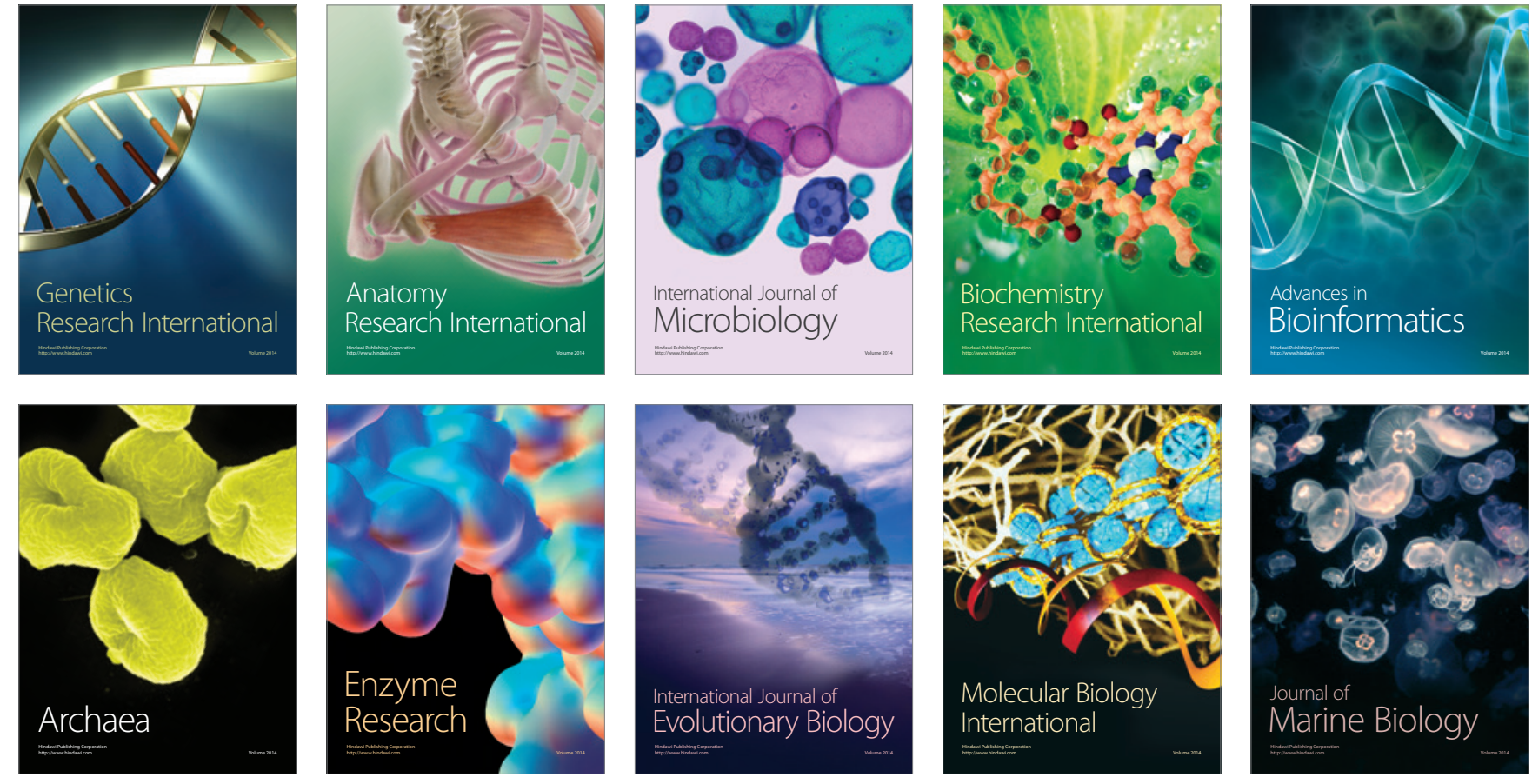